\title{
Conductometric Gas Nanosensors
}

\author{
Girolamo Di Francia, Brigida Alfano, and Vera La Ferrara \\ Italian Agency for New Technologies, Energy, and the Environment (ENEA), CR-Portici P.le E. Fermi 1, \\ 80055 Napoli, Italy
}

Correspondence should be addressed to Girolamo Di Francia, difrancia@portici.enea.it

Received 29 December 2008; Accepted 20 April 2009

Recommended by Giorgio Sberveglieri

This paper presents a review of the current research activities in the field of gas nanosensors. Nanomaterials are characterized by physical and chemical properties that differ from their macroscopic counterparts and, in particular, by an enhanced chemical reactivity even at room temperature. This effect has stimulated the development of chemical sensors based on several different nanomaterials. Here we focus most attention on carbon nanotubes, silicon and metal oxide nanoparticles and metal nanowires. After introducing a few general definitions a discussion on the fundamental properties of the nanostate used in the sensor field is presented and several nanosensors, based on the aforementioned nanomaterials, are discussed. Finally, some personal conclusions will be drawn.

Copyright ( 2009 Girolamo Di Francia et al. This is an open access article distributed under the Creative Commons Attribution License, which permits unrestricted use, distribution, and reproduction in any medium, provided the original work is properly cited.

\section{Introduction}

Gopel first introduced the term "chemical nanosensor" in the early nineties. At that time, only a minor interest was reserved to nanotechnologies by the scientific community and the number of yearly papers regarding this topic was less 5\% than the actual number. In its early formulation the term was meant to describe, in most cases, a chemical sensor characterized by the matching of solid state materials with suitable "key-lock" structures, often biostructures, capable of molecular recognition. In this frame, the natural choice for the solid state material was then a structure on the nanoscale $[1,2]$.

A chemical nanosensor can be defined as an electronic device, consisting of a transducer and a sensitive element that relies, for its operating mechanism, on at least one of the physical and chemical properties typical of the nanostate. Basically it operates as any other chemical sensor: a charge transfer occurs between molecules and a "sensitive" material, resulting in an electrical and/or optical signal that is related to the molecules type and number. However unlike macroscopic sensors, chemical nanosensors can take advantage of the merging of four different features typical of the nanostate: (1) the quantum confinement, (2) the surfaceto-volume ratio, $\mathrm{S} / \mathrm{V}$, with a specific surface termination and nanoparticle (NP) doping, (3) the NP morphology and aggregation, and (4) the nanomaterial agglomeration state (the word nanoparticle, NP, is here used to describe, in general, any kind of structure with at least one of its dimension in the nanorange. Sometimes expressions such as nanowire, nanodot, or nanotube will be used, when a more precise reference to the morphology is required). These properties improve the sensitive material behavior of room temperature (RT) operating devices and high sensitivities have been demonstrated. In fact, in the last 10 years almost 2000 papers referring to "chemical nanosensors" have been published and the field seems to be one of the most immediate and promising sectors for the application of nanotechnologies [3]. This rapid growth can be attributed largely to recent advances in nanotechnologies that enabled the synthesis and engineering of materials to realize devices that exhibit functionalities specifically originated by their nanostate [4].

Here we present a review of current research activities on gas nanosensors. The paper is divided into three sections. In the first section the operating mechanisms of chemical nanosensors will be discussed in terms of the four features outlined above. In the second section we review the current research activities in this field, discussing the performances of devices mainly based on carbon nanotubes, nanosilicon, 


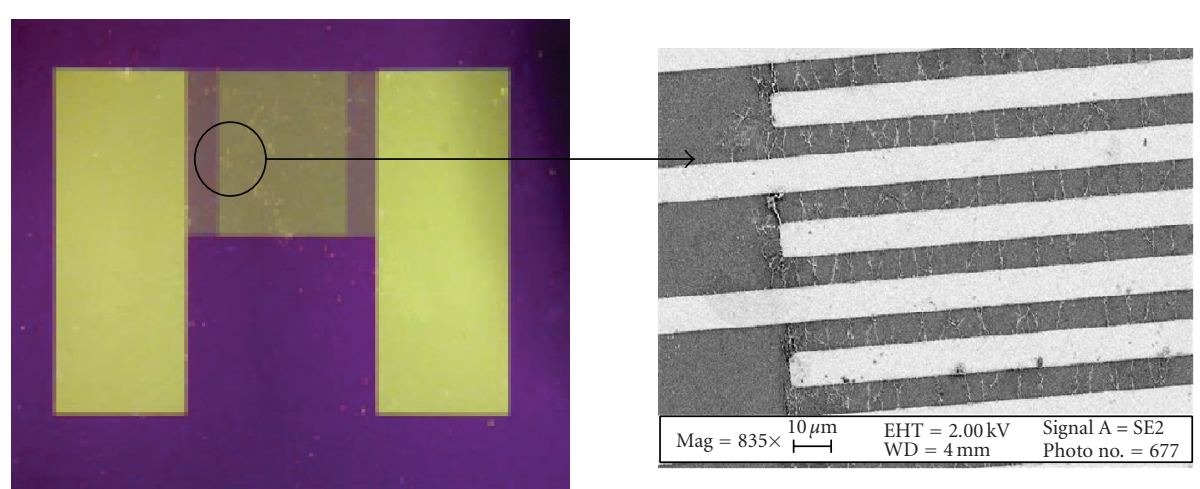

FIGURE 1: Optical and electronic images of a hydrogen nanosensor fabricated by the authors. An array of palladium nanowires is assembled, by means of ac dielectrophoresis, directly onto a silicon chip. Wires grow almost perpendicularly to interdigitated electrodes. The RT response of the devices depends on the size and morphology of the sensitive elements. Electric current changes can be reversible and greater than $140 \%$ in $4 \% \mathrm{H}_{2}$.

nanometal oxides, and nanometals, which account for more than $90 \%$ of the published papers. In the last section some conclusions are drawn, with a focus on device design and proposed sensing. For the sake of brevity we will not deal with polymer nanocomposite-based chemical sensors, except in a few cases. It should be noted that chemical nanosensors were reviewed, although with different approaches, in 2006 and 2007 by Huang and Choi, Jiménez-Cadena et al., and Riu et al. [5-7].

\section{Properties of the Nanostate}

There is not an exact understanding of the mechanisms for quantum confinement, surface-to-volume ratio, NP morphology, and aggregation/agglomeration states to control nanomaterial sensitivity. Nevertheless, there is clear evidence for nanostate-enhanced chemical reactivity [8]. In the following an account of the principal findings related to each of the four features is presented.

2.1. Quantum Confinement. In a metallic material, quantum confinement (QC) plays a key role in setting up and determining material properties when one dimension is comparable to the de Broglie wavelength which, for a typical metal such as copper, is a fraction of an nm. However, unless low temperatures and high magnetic fields are employed, scattering or incoherent phenomena prevent the observation of QC related effects, even in the nanorange. For a nonmetallic material the comparative dimension is the Bohr exciton radius which falls, in many cases, in the range of 1 to $10 \mathrm{~nm}$. Since the exciton binding energy increases for decreasing the confinement dimension, a nonmetallic nanomaterial can exhibit quantum effects even around room temperature, opening the way to fabrication of QC-based nanosensors. In this range, ionization potentials or chemical affinities, just to mention two of the quantities classically considered unscalable, are shown to depend on the size and are different from the atomic and the bulk extrema [9]. In other words nanoscale particles can be considered as "new," size-dependent, solid state materials with their own chemical functionalities. In this respect, for each element a new class of materials originates and new devices and systems can be engineered by virtue of their size.

A very interesting consequence, as far as sensors are concerned, is that these materials exhibit a different chemical activity than their bulk counterparts $[10,11]$. For instance, Brus has shown that in a semiconductor nanocrystal the rate of charge transfer, $k_{q}$, is greatly enhanced and mainly determined by quantum confinement effects [12, 13]. More recently Di Francia et al. have modeled the interaction between a Silicon NP and a gaseous ensemble [14]. Neglecting diffusion effects, the model expresses the reaction rate constant, $k_{q}$, by the following classical relationship:

$$
k_{q}=p * Z * \exp \left(-\frac{\Delta G^{*}}{K_{B} T}\right)
$$

Here $p$ is the probability of electron transfer in the activated complex and $\Delta G^{*}$ is the free energy required to form the activated complex from the separate reactants $[15,16]$. For an adiabatic reaction $p \approx 1$, while in the nonadiabatic case $p<1 . Z$ is the collision frequency, which has a linear dependence on the reactants cross-sections [17]. $Z$ is expressed in Torr ${ }^{-1} \mathrm{~s}^{-1}$ for reactions in the gas phase.

According to Marcus theory:

$$
\Delta G^{*}=\frac{1}{4 \lambda}\left(\lambda+\Delta G_{0}\right)^{2}
$$

where $\Delta G_{0}$ is the standard free energy of the reaction and $\lambda$ is defined as the "reorganization term" [16]. $\lambda$ is a parameter related to the reorganization of the reactants electronic levels upon the electron transfer event and it is the sum of an inner and an outer term: $\lambda=\lambda_{i}+\lambda_{0}$ [16]. For gaseous reactions the last term is negligible and $\lambda=\lambda_{i}$ [18]. A similar expression holds both for adiabatic $(p \approx 1)$ and nonadiabatic $(p<1)$ reactions, although with a suitable redefinition of the various terms [15]. In the latter case $p$ must be treated quantum-mechanically and is a function of the reagentproduct wavefunctions overlap. When quantum effects are exhibited, $Z, p$, and $\Delta G^{*}$ will depend, in general, on the 


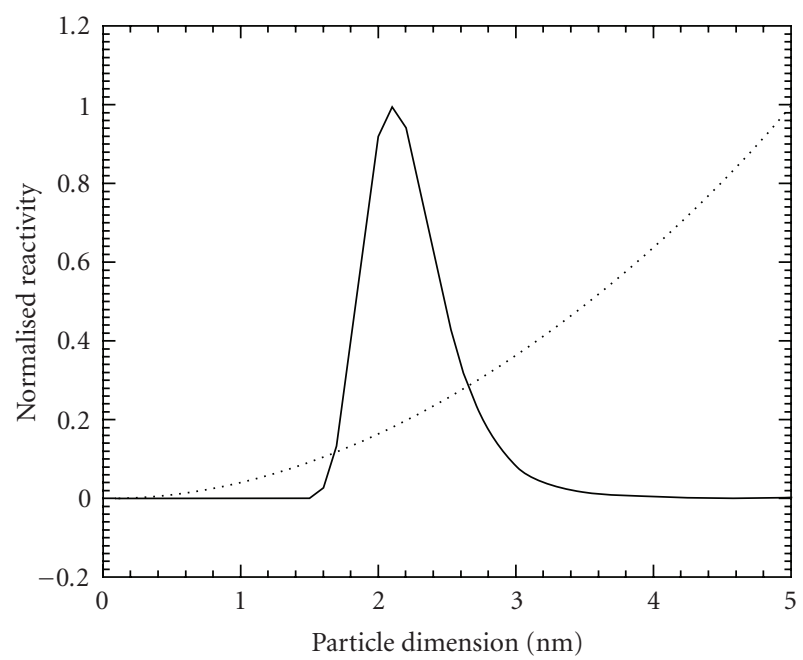

Figure 2: Plot of (3) where the resonant rate constant and the sole surface effect (dashed) are reported for the case of a silicon nanoparticle.

confinement energy $E_{c}$, that is, on the particle size $d_{p}$. For the case investigated the reaction rate constants for unpassivated and passivated nanoparticles are given, respectively, by

$$
k_{q}=Z^{\prime} * d_{p}^{2} * \exp \left[-\frac{1}{4 K_{B} T \lambda_{v}}\left(\lambda_{v}^{\prime}-E_{c}\left(d_{p}\right)\right)^{2}\right],
$$

where $\lambda_{v}^{\prime}=\lambda_{v}-\left(E_{O_{2}}-E_{g}\right)$, or

$$
k_{q}=Z^{\prime} * d_{p}^{2} * \exp \left(-\gamma * d_{p}\right)
$$

where $\gamma$ is a scaling factor [14].

For both situations the model predicts the existence of a resonant energy (i.e., of a resonant dimension) that strongly enhances the NP-molecule charge transfer. In Figure 2 the effect is shown for the case of the interaction between a silicon NP and molecular oxygen. Two conclusions can be drawn from the model. First, since the characteristics of the electron transfer resonance are only determined by the specificity of the NP-molecule interaction, nanosensors relying on this effect could be highly selective and their response tuned towards a specific analyte by means of proper selection of the nanoparticle material and size. Second, "quantum" sensitivity will mainly depend on the ability to fabricate nanosensors operating on the highest number of singly operating NPs. This is probably the most difficult task to achieve since NP ensembles usually show physical properties that are very different from the individual components [19].

2.2. S/V Ratio and Surface Termination. According to (3) and (4), below and above the resonant region it is the surface that mainly determines the nanosensor performance. The surface-to-volume ratio, $\mathrm{S} / \mathrm{V}$, and the surface termination shape the specificity of the nanostate since surface and bulk states compete for control of the materials physical and chemical properties [20]. This effect is strongly dependent

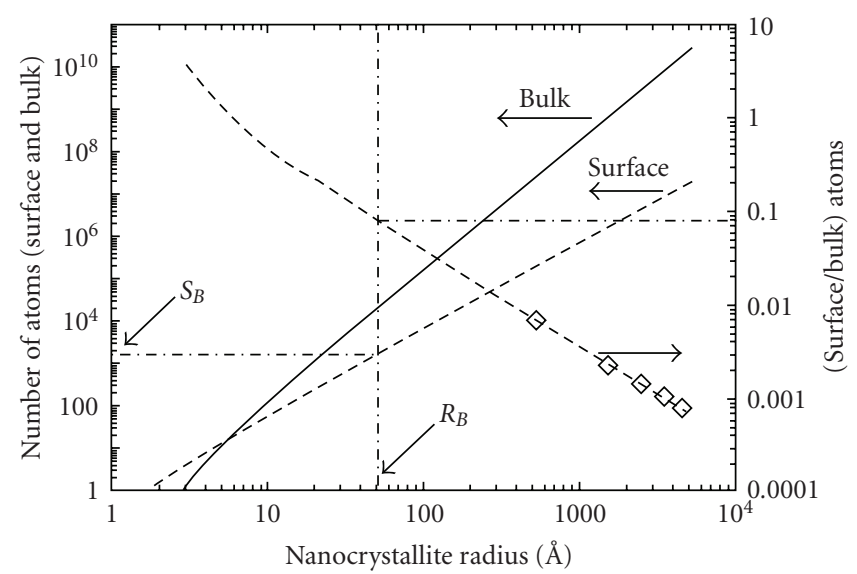

FIGURE 3: Number of surface and bulk atoms for a crystalline silicon spherical NP versus its bulk dimension. $R_{b}$ is the Bohr exciton radius and $S_{b}$ the corresponding number of NP surface atoms [22].

on the surface termination and becomes more evident the smaller the NP dimensions are, even if quantum effects are not intense [21]. In Figure 3 the number of surface and bulk atoms has been computed and reported for the case of a crystalline silicon spherical NP versus its bulk dimension. The right axis shows that for decreasing nanocrystalline radius, the $\mathrm{S} / \mathrm{V}$ ratio rapidly increases reaching values around 10\% for NP dimensions just below the silicon Bohr exciton radius [22]. As a result, the interaction cross-section decreases and surface states, which are more sensitive to external molecules, increasingly determine NP physical and chemical properties. The latter effect is more pronounced when defects, surface adsorbed species, or an NP doping are present $[21,23]$.

2.3. NP Morphology. For nanoparticles exhibiting the same $\mathrm{S} / \mathrm{V}$ ratio, morphological differences may result in different chemical properties. For example convex surface structures have lower dissolution rates than concave ones [24]. Convex structures are also thermodynamically less stable, so that these particles can suffer preferential dissolution and have higher equilibrium solubility $[25,26]$. In some cases their equilibrium solubility can even be above saturation concentrations, leading to precipitation and growth of aggregates. This thermodynamic instability can be particularly strong, resulting in forms of "natural attachment" with defect-free structures and homogeneous crystal orientation [27]. NP aggregates are the most common form for a nanomaterial with physical and chemical properties which are different from basic block, although strongly dependent on it [19]. They are very complex to model since they can be assimilated to macroscopic quantum confined structures. A possibile way to overcome this problem is through the use of NP specific surface passivating treatments that, however, strongly deprive reactivity.

2.4. NP Agglomeration. NPs and NP aggregates very often tend to form agglomerates. This further complicates the 
problem introducing a new route for physical and chemical property modification. Agglomerates could be considered, technologically speaking, as the "natural" NPs state, characterized, for instance, by nanowires (NWs), bundles, or nanodot pellets, which are generally difficult to control in terms of number of constituents, shape, morphology, and so forth. Nanodevices fabrication requires a standard platform for technological process manufacturing and this, in turn, necessitates well-defined technological treatments to remove agglomerates. This is a research area that is still in its infancy.

The unique physical and chemical properties that nanoscale materials exhibit stem from a competition/ merging of the above elements, whose relative weights are mainly determined by the way the materials are engineered. Top down approaches provide highly controllable processes (such as the lithographic process) and lead, in general, to the fabrication of few structures, even single quantum dots, whose physical properties can be finely predicted theoretically or to synthesize a much larger number of nanostructures, as in the case of the electrochemical etching, by means of self-adjusting mechanisms, still difficult to model. In both cases agglomeration is not exhibited, but aggregation directly determines the physical properties, at least in the latter case. "Bottom up" approaches, such as vacuum deposition or electrochemical growth, show similar features. Agglomeration, however, is usually observed in this case [28].

\section{Nanosensors}

In the following, an overview of the status of the current research activities in this field is delineated. Due to the large number of papers, we selected the works that, in our view, better describe the evolution of this field, mainly in the last few years.

3.1. Carbon Nanotubes. Tubes are potentially very interesting in the sensor field since they are characterized by high, theoretically infinite, S/V ratio. Kong et al. first reported on a dramatic decrease, or increase, of the electrical resistance, measured by means of scanning tunneling microscopy, in single-walled carbon nanotubes (SWCNT) exposed to $\mathrm{NO}_{2}$, or $\mathrm{NH}_{3}$, respectively, [29]. In the former case the increased electrical conductivity in $\mathrm{NO}_{2}$ was attributed to a partial charge transfer from the SWCNT to $\mathrm{NO}_{2}$, resulting in an increase in the hole concentration. In the latter case, some not clearly defined intermediate species were suggested to have played a key role. SWCNTs have also been shown to exhibit an extreme oxygen sensitivity [30]. In this case, an increase in the electrical conductivity in an oxidizing environment has been reported and it was suggested that defects could play a major role in the mechanism. The same group had previously reported on some singularities appearing in the electrical conduction of SWCNTs and similarly attributed this to the presence of some kind of defect [31].

Following that finding, several CNT-based nanosensors began to be investigated. Li et al. proposed a simple resistive device, shown in Figure 4, fabricated by casting a solution

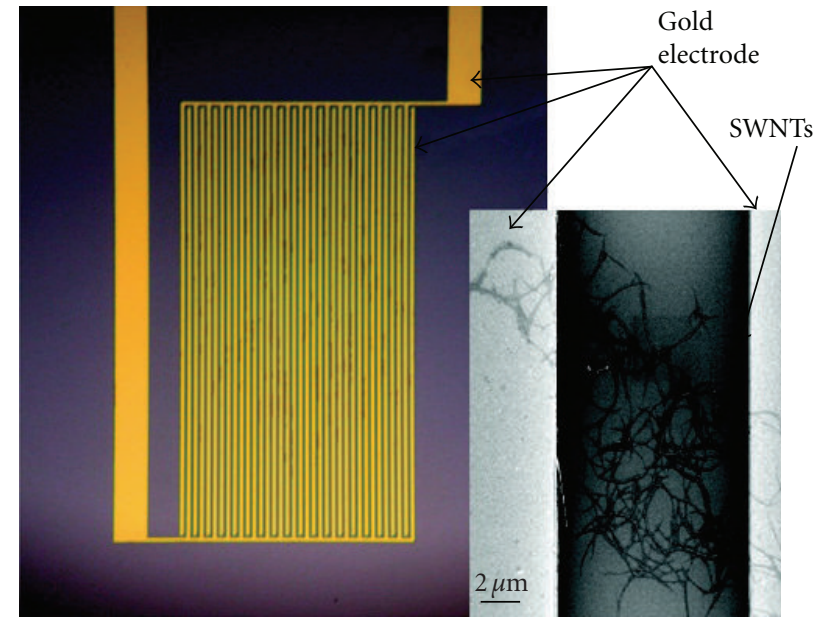

FIgURE 4: $\mathrm{NO}_{2}$ and nitrotoluene nanosensor. Images show the interdigitated electrodes and the bundle of SWCNTs across the two gold electrodes working as the sensitive material. (Reprinted from [32], copyright 2003, with permission from the American Chemical Society.)

of purified SWCNT in dimethylformamide on a silicon substrate [32]. The device operated at room temperature and exhibited a very high sensitivity to $\mathrm{NO}_{2}$ and nitrotoluene with $44 \mathrm{ppb}$ and $262 \mathrm{ppb}$ detection limits, respectively, in $\mathrm{N}_{2}$. It was speculated that the operating mechanism was related to charge transfer on individual nanowires, with additional hopping effects modulating the conductivity.

The following year, the same group reported on an SWCNT-based gas sensor, specifically designed for methane with an operating range in dry air between 6 and $100 \mathrm{ppm}$ [33]. The device was fabricated by casting, using a suspension of purified SWCNT in deionized water (DIW) where sputtered $\mathrm{Pd}$ nanoparticles were dispersed. These weak complexes allowed methane adsorption along the NW walls, changing the conductivity by means of a charge transfer mechanism. This group also stressed, for the first time, the requirement of "sensor training": the device was observed to improve its performances with use (mainly in terms of baseline stabilization). The adopted process reflects the temperature conditioning processes typical of semiconductor oxide-based chemical sensors.

Valentini et al. then proposed another interesting methane sensor based on CNTs and fabricated on a silicon wafer, with $\mathrm{Pt}$ interdigitated (IDE) contacts, a platinum heater and operating around $1000 \mathrm{ppm}$. The device switched from $\mathrm{p}$-type to n-type upon exposure and the possible role of defects adsorbed atmospheric oxygen, acting as intermediate towards other external gas molecules, was suggested [34].

The feasibility of a simple and original fabrication process was demonstrated by Wongwiriyapan et al., by selectively growing SWCNTs directly onto an alumina substrate, patterned with Pt IDE and coated with e-gun deposited Al and Fe clusters acting as catalysts. The device, shown in Figure 5, operates as an $\mathrm{NO}_{2}$ SWCNT-based gas sensors with a detection limit down to $50 \mathrm{ppb}$ [35]. 


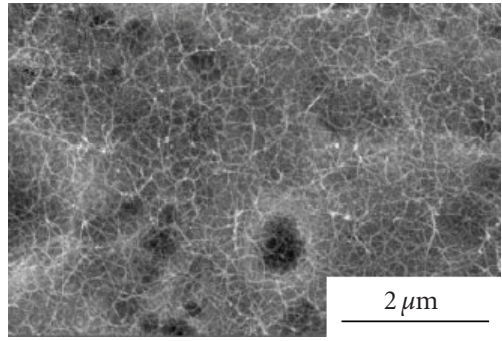

(a)

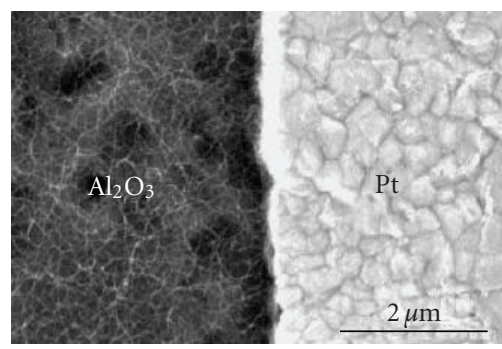

(b)

FIGURE 5: The original fabrication process demonstrated by Wongwiriyapan et al. SEM images show as-grown SWNT networks (a) on alumina substrate, and (b) at the boundary between an alumina layer and Pt electrode. (Reprinted with permission from [35]. Copyright JJAP 2005.)

Similar sensitivities towards $\mathrm{NO}_{2}$ in dry air (up to $100 \mathrm{ppb}$ ) were claimed by Penza et al. This group fabricated a multiwalled carbon nanotube (MWCNT)-based gas sensor on an Alumina substrate. Fe was used as a catalyst for the growth. The enhanced sensitivity was obtained using Pt and $\mathrm{Au}$ as reaction catalysts and explained in terms of a spillover mechanism. $\mathrm{NH}_{3}$ sensitivities up to $5 \mathrm{ppm}$ were reported [36].

Several sensor devices based on a Field Effect Transistor (FET) architecture have also been proposed. An FET sensor has been fabricated using the $\mathrm{Si} / \mathrm{SiO}_{2}$ substrate as the gate and depositing Mo both as catalyst, for SWCNT growth and to form source/drain (S/D) contacts to the device. Arrays of CNTs were then deposited as bridges between $\mathrm{S} / \mathrm{D}$ electrodes. The device, coated with Polyethylenemine or Nafion, exhibited detection limits of $100 \mathrm{ppt}$ towards $\mathrm{NO}_{2}$ and $10 \mathrm{ppm}$ towards $\mathrm{NH}_{3}$. In both cases the electrical current decreased. Recovery was accomplished using UV illumination [37].

Similarly, an $\mathrm{NO}_{x}$ and $\mathrm{NH}_{3}$ SWCNTs-based chemical sensor has been fabricated by means of dielectrophoretic process on an FET structure. It was found that $\mathrm{NH}_{3}$ reduces the conductivity because of the charge transfer to the SWCNT, whereas $\mathrm{NO}_{x}$ induces an opposite effect [38].

In order to improve the sensitivity of SWCNT-based sensor, nanotube functionalization has been suggested. By means of an electrochemical process, SWCNTs have been, for instance, functionalized with polyaniline (PANI). The PANI-SWCNT composite behavior has been tested in $\mathrm{NH}_{3}$, exhibiting a detection limit of $50 \mathrm{ppb}$. The response time at room temperature is of the order of minutes and the recovery time is a few hours [39].

Nguyen's group fabricated a gas sensor from an SWCNT powder by the screen-printing method followed by an annealing treatment. The sensor has been tested up to $5 \mathrm{ppm}$ of $\mathrm{NH}_{3}$ diluited in $500 \mathrm{sccm} \mathrm{N} \mathrm{N}_{2}$ at room temperature. The sensitivity increased as the gas concentration increased but diminished when the $\mathrm{NH}_{3}$ concentration reached $40 \mathrm{ppm}$. Sensor recovery was achieved by increasing the carrier flow or heating the device during the desorption step [40].

MWCNTs synthesized under ambient conditions and coated with $\mathrm{SnO}_{2}$ were investigated as sensitive elements in a sensor that exhibited fast responses to liquefied petroleum gas (LPG) and ethanol $\left(\mathrm{C}_{2} \mathrm{H}_{5} \mathrm{OH}\right)$ with a recovery time of only a few seconds [41].

A thiol functionalized MWCNT-based chemical sensor was designed and developed for the detection of the first four fundamental aliphatic hydrocarbons: methanol $\left(\mathrm{CH}_{3} \mathrm{OH}\right)$, ethanol $\left(\mathrm{C}_{2} \mathrm{H}_{5} \mathrm{OH}\right)$, propanol $\left(\mathrm{C}_{3} \mathrm{H}_{7} \mathrm{OH}\right)$, and butanol $\left(\mathrm{C}_{4} \mathrm{H}_{9} \mathrm{OH}\right)$. High degrees of selectivity and sensitivity up to a detection concentration of $1 \mathrm{ppm}$ have been demonstrated. It was shown that in the presence of a chemical species, the surface of the nanotubes undergoes a change resulting in a shift of the resonant frequency peak [42].

Single-walled carbon nanohorns (SWNHs), produced by the gas-injected arc-in-water method, have been used by Suehiro et al. to fabricate a room temperature $\mathrm{NO}_{2}$ and $\mathrm{NH}_{3}$ nanosensors. Agglomerated SWNHs were deposited on a glass substrate between metal electrodes and manipulated under dielectrophoresis. It was found that conductance of the DEP-fabricated SWCNHs sensor increased or decreased upon exposure to ppm-levels of $\mathrm{NO}_{2}$ or $\mathrm{NH}_{3}$, respectively, [43].

To detect $\mathrm{NO}_{2}$, Lee et al. deposited, by casting, a dispersion of as-grown SWCNT powder into dimethylformamide on a pair of interdigitated electrodes. A $350^{\circ} \mathrm{C}$ annealing was used to eliminate the DMF molecules adsorbed on the surface. The sensors were exposed to $\mathrm{NO}_{2}$ concentrations in the range of $3 \mathrm{ppm}$ to $10 \mathrm{ppm}$ and the gas sensing property was assigned to a direct charge transfer from the physically adsorbed molecules to the individual p-type semiconducting SWCNTs [44].

In order to improve device selectivity, Suehiro et al. proposed a liquid-phase electrochemical reaction to realize a Pd-functionalized CNT hydrogen sensor. The CNTs were immersed in a palladium acetate solution together with a graphite rod. DC voltage was applied so that palladium acetate could be reduced and catalytic Pd could be electrodeposited on the CNT surface. The CNT sensor reversibly responded to hydrogen gas in air in the concentration range from $0.05 \%$ to $1 \%$ at room temperature [45].

Sin et al. realized alcohol sensors by depositing bundles of chemically functionalized multiwalled carbon nanotubes across $\mathrm{Au}$ electrodes on an $\mathrm{SiO}_{2} / \mathrm{Si}$ substrate using an $\mathrm{AC}$ electrophoretic technique. The multiwalled carbon nanotubes were chemically functionalized with $\mathrm{COOH}$ groups by oxidation. It was found that the sensors were selective towards water vapors and alcohol vapors in air. The sensor response was linear for alcohol vapor concentrations from 
$1 \mathrm{ppm}$ to $21 \mathrm{ppm}$ with a detection limit of $0.9 \mathrm{ppm}$. The response time was around 1 second. Recovery was obtained by passing a current of $100 \mu \mathrm{A}-200 \mu \mathrm{A}$ for about $100-200$ seconds through the sensing elements [46].

Finally, an interesting approach was proposed by Vieira et al., by combining single-walled carbon nanotubes and poly(3,3-dialkyl-quarterthiophone). The devices containing only nanotubes or pure polymer provided minimal response, whereas the nanocomposite material ( $1 \mathrm{wt} . \%$ of nanotubes in the polymer) exhibited excellent sensitivity and selectivity to hydrogen, ammonia, and acetone. Moreover they observed that even small amounts of gas doping (10 ppb) resulted in exponential changes in the overall conductivity profile of the nanocomposite sensor, thus anticipating an element of "gain" within the chemical sensor. The proposed mechanism takes into account an effect of modulation of the polymer electrical conductivity induced by the SWCNT interaction with the analyte [47].

In Table 1 an overview of the results, presented above, is shown. Sensors generally operate at RT. Responsivity is fairly high and recovery is often observed, although with long characteristic times. In most cases, some sort of conditioning process has been performed.

3.2. Crystalline Silicon. The physical properties of crystalline silicon are quite insensitive to the environment. Actually, this is one of its relevant characteristics as an electronic material. It is then quite surprising to observe that when reduced to the nanoscale, in a porous structure, crystalline silicon strongly reacts, even explosively, with various analytes [48, 49]. The silicon Bohr exciton radius is about $5 \mathrm{~nm}$ and when silicon is electrochemically engraved, a porous silicon (PS) structure with wall thicknesses in the range of $2 \mathrm{~nm}$ to $5 \mathrm{~nm}$ is formed [50]. The resulting nanocrystallites show novel properties, determined by the quantum confinement and by surface defects that play a key role in determining material physical properties, since the structure is characterized by a high $\mathrm{S} / \mathrm{V}$ ratio that roughly increases with the inverse of the wall thickness $[51,52]$. PS high chemical reactivity towards the environment has stimulated great interest in the sensor field. Properties such as its photoluminescence quenching and/or the electrical conductivity deep change, induced by molecules adsorbed onto its surface, are very interesting for gas sensor applications especially taking into account that they are observed at room temperature. Therefore, several PS-based sensor devices have been investigated, operating on both optical and electrical effects.

In Table 2 a summary of the chemical families detected with such devices is given.

Although very high sensitivities have often been reported, selectivity is rarely an issue $[80,81]$. Actually, the instability of the native surface termination is the major barrier preventing wide applications of PS in the sensor field. In typical porous silicon formation the material surface, although mainly characterized by a stable $\mathrm{Si}-\mathrm{H}$ coverage, is partially defected and prolonged exposure to air, in standard operating conditions, can deteriorate the passivation which is required for the material to be effectively used in sensor technology.
Several methods to overcome this problem have been investigated in order to overcome this problem. For instance, Massera et al. demonstrated that stabilizing its surface with a prolonged exposure to high $\mathrm{NO}_{2}$ concentrations prior to use greatly improved the electrical performance of a PS $\mathrm{NO}_{2}$ gas sensor [82]. Recently, Ali et al. investigated the effect of surface passivation in a hydrogen sensor based on Porous silicon [83]. Two types of samples were prepared, one with typical HF anodizing solution and the other with the addition of $\mathrm{H}_{2} \mathrm{O}_{2}$. The device based on peroxide treated PS showed a better electrical (I-V) sensitivity, which was attributed to a more efficient surface passivation, confirmed by the Fourier transform infrared (FT-IR) measurements. Lewis et al. observed that a novel process for device metal coating using electronless deposition provided enhanced sensitivity and selectivity to $\mathrm{NO}_{x}, \mathrm{CO}$, and $\mathrm{NH}_{3}$ [84]. Rahimi and Iraji zad presented another method to improve the selectivity and sensitivity of a PS-based hydrogen gas sensor. By means of an electronless process, Pd nanoparticles were deposited onto a porous silicon surface. Hydrogen sensing occurs on the basis of a change in the Schottky barrier height at the silicon-palladium interface. Variations of the electrical resistance, at room temperature, in the presence of diluted hydrogen concentrations down to levels of only a few thousand ppm, were observed [85].

Mahmoudi et al. showed how sensitive and reversible detection of $\mathrm{CO}_{2}$ and propane could be achieved by means of photoluminescence-quenching modified porous Si [86]. In this case, porous silicon coated with a hydrocarbon group $\left(\mathrm{CH}_{x}\right)$ was annealed at different temperatures, allowing the carbon to react with silicon and to produce $\mathrm{SiC}$. An intense blue light is emitted from the thermally carbonized PS surface after annealing at $600^{\circ} \mathrm{C}$. Good sensitivity for organic solvent detection was observed after thermal annealing of microcavity devices based on this technology [87].

A completely different approach to silicon-based nanosensors, although mainly investigated for biosensors, is to exploit the properties of silicon nanowires. Hahm and Lieber first reported on a very sensitive DNA sensor fabricated by modifying the surface of a silicon nanowire. In this case the effect of surface states on the silicon nanowire quantum properties observed at the nanoscale could play an effective role in the device sensitivity [88]. This effect is similar to the one reported by Di Francia et al. and observed on suitably functionalised porous silicon [89]. The effect of different environments on silicon nanowires has been also investigated, opening the way to silicon nanowire-based chemical sensors. For instance Zhou et al. first reported on a $\mathrm{NH}_{3}$ and $\mathrm{RH}$ sensitive and reversible sensors based, as shown in Figure 6, on bundles of silicon nanowires [90]. Recent accounts on these approaches can be found in $[91,92]$.

3.3. Metal Oxides. Metal Oxides (MOX) possess a broad range of electronic, chemical, and physical properties that are often highly sensitive to changes in the chemical environment. In fact, most commercial solid state chemical sensors are based on appropriately structured and doped metal 
TABLE 1: CNT-based nanosensor properties and performances. Sensors generally operate at RT. In several cases some sort of conditioning process is used for improving device characteristics. Recovery is obtained with quite empirical approaches.

\begin{tabular}{|c|c|c|c|c|c|c|}
\hline Material & $\begin{array}{l}\text { Chemical species } \\
\text { detected (carrier) }\end{array}$ & Range & Recovery & Conditioning & notes & Ref. \\
\hline SWCNT & $\begin{array}{l}\mathrm{NO}_{2}\left(\mathrm{~N}_{2}\right) \\
\text { Nitrotol. }\left(\mathrm{N}_{2}\right)\end{array}$ & 10 s to $100 \mathrm{sppb}$ & $\begin{array}{l}\text { Yes, slow, better } \\
\text { with UV light }\end{array}$ & No & & [32] \\
\hline $\begin{array}{l}\text { SWCNT (Pd } \\
\text { charged) }\end{array}$ & $\mathrm{CH}_{4}$ (air) & $10-100 \mathrm{ppm}$ & $\begin{array}{l}\text { Yes, slow, better } \\
\text { with UV light }\end{array}$ & Yes & Operated at $40^{\circ} \mathrm{C}$ & [33] \\
\hline CNT & $\begin{array}{l}\mathrm{CH}_{4} \text { (vacuum) } \\
\mathrm{O}_{2} \text { (vacuum) }\end{array}$ & $0.01-12 \mathrm{mbar}$ & No & No & & {$[34]$} \\
\hline SWCNT & $\mathrm{NO}_{2}$ & $50 \mathrm{ppb}$ & Not Available (NA) & No & Carrier data NA & [35] \\
\hline MWCNT & $\begin{array}{l}\mathrm{NO}_{2} \text { (dry air) } \\
\mathrm{NH}_{3} \text { (dry air) }\end{array}$ & $\begin{array}{l}100 \mathrm{ppb} \\
5 \mathrm{ppm}\end{array}$ & Yes, slow & No & Operated at $\mathrm{T}>150^{\circ} \mathrm{C}$ & [36] \\
\hline SWCNT & $\begin{array}{l}\mathrm{NO}_{2} ; \mathrm{NH} 3 \text { in } \mathrm{Ar} \\
\text { diluited in air }\end{array}$ & $\begin{array}{l}100 \mathrm{ppt} \\
100 \mathrm{ppm}\end{array}$ & Yes with UV light & No & $\begin{array}{l}\text { Selectivity obtained with } \\
\text { polymer coating }\end{array}$ & [37] \\
\hline $\begin{array}{l}\text { Commercial } \\
\text { SWCNT }\end{array}$ & $\begin{array}{l}\mathrm{NH}_{3}\left(\mathrm{~N}_{2}\right) \\
\mathrm{NO}_{x}\left(\mathrm{~N}_{2}\right)\end{array}$ & $\begin{array}{l}30 \% \text { in aqueous } \\
\text { solution } \\
13.5 \mathrm{ppm}\end{array}$ & $\begin{array}{l}\text { Yes with } \\
\text { electrostatic } \\
\text { perturbation }\end{array}$ & Yes & $\begin{array}{l}\text { Sensitivity depends on gate } \\
\text { voltage. } \mathrm{NH}_{3} \text { reduces the } \\
\text { conductivity; } \mathrm{NO}_{x} \text { induces an } \\
\text { opposite effect }\end{array}$ & [38] \\
\hline $\begin{array}{l}\text { PANI-SWCNT } \\
\text { network }\end{array}$ & $\mathrm{NH}_{3}$ & $50 \mathrm{ppb}_{v}$ & Yes, with argon & Yes & $\begin{array}{l}\text { At room temperature sensor } \\
\text { response is completely reversible }\end{array}$ & [39] \\
\hline SWCNT & $\mathrm{NH}_{3}\left(\mathrm{~N}_{2}\right)$ & $5 \mathrm{ppm}$ & $\begin{array}{l}\text { Yes, increasing the } \\
\text { carrier flow or } \\
\text { heating during the } \\
\text { desorption }\end{array}$ & Yes & $\begin{array}{l}\text { Annealing pretreatment } \\
\text { increased the sensor sensitivity. } \\
\text { Sensitivity diminished when } \\
\mathrm{NH}_{3} \text { concentration reached } \\
40 \text { ppm }\end{array}$ & {$[40]$} \\
\hline $\begin{array}{l}\text { MWCNT }\left(\mathrm{SnO}_{2}\right. \\
\text { particles coated) }\end{array}$ & $\begin{array}{l}\text { LPG } \\
\mathrm{C}_{2} \mathrm{H}_{5} \mathrm{OH} \text { in } 50 \% \\
\mathrm{RH}\end{array}$ & $\begin{array}{l}100-1000 \mathrm{ppm} \\
10-200 \mathrm{ppm}\end{array}$ & Yes (few seconds) & Yes & $\begin{array}{l}\text { Working temperature } 325^{\circ} \mathrm{C} \text {. } \\
\text { Sensor response is linear with gas } \\
\text { concentrations }\end{array}$ & [41] \\
\hline $\begin{array}{l}\text { MWCNT (thiol } \\
\text { funct.) }\end{array}$ & $\begin{array}{l}\mathrm{CH}_{3} \mathrm{OH} \mathrm{C} \mathrm{C}_{2} \mathrm{H}_{5} \mathrm{OH} \\
\mathrm{C}_{3} \mathrm{H}_{7} \mathrm{OH} \\
\mathrm{C}_{4} \mathrm{H}_{9} \mathrm{OH} \\
\text { (DI water) }\end{array}$ & $1 \mathrm{ppm}$ & NA & NA & $\begin{array}{l}\text { Resonant freq. Shift. Freq. } \\
\text { response is due to the binding } \\
\text { between Thiol group and ionic } \\
\text { hydrocarbon }\end{array}$ & [42] \\
\hline SWCNT & $\mathrm{NO}_{2}$ & $3-10 \mathrm{ppm}$ & No & NA & $\begin{array}{l}\text { Dispersion of SWCNT powder } \\
\text { into dimethylformamide }\end{array}$ & {$[44]$} \\
\hline $\begin{array}{l}\text { Commercial } \\
\text { SWCNT }\end{array}$ & $\mathrm{H}_{2}$ (air) & $0.05-1 \%$ & Yes & No & Pd-functionalized & {$[45]$} \\
\hline $\begin{array}{l}\text { Commercial } \\
\text { SWCNT }\end{array}$ & alcohol & $1-21 \mathrm{ppm}$ & Yes & No & Recovery by current injection & {$[46]$} \\
\hline $\begin{array}{l}\text { Commercial } \\
\text { SWCNT }\end{array}$ & $\mathrm{NH}_{3}$ and $\mathrm{H}_{2}$ & $0.01-1000 \mathrm{ppm}$ & NA & NA & $\begin{array}{l}\text { Composite with conducting } \\
\text { polymers }\end{array}$ & {$[47]$} \\
\hline
\end{tabular}

oxides (mainly $\mathrm{SnO}_{2}$ and $\mathrm{ZnO}$ ) that have proved capable of detecting a variety of gases with high sensitivity, good stability and also for low production cost.

The fundamental sensing mechanism for most metal oxide-based gas sensors relies on the change in electrical conductivity due to charge transfer between surface complexes, such as $\mathrm{O}^{-}, \mathrm{O}_{2}^{-}, \mathrm{H}^{+}$, and $\mathrm{OH}^{-}$, and interacting molecules. Normally this process requires an activation energy so that classical MOX sensors only operate at high temperatures, generally above $200^{\circ} \mathrm{C}$ [93]. This means that power consumption is a problem that is becoming more and more urgent in view of the new concepts of pervasive sensing, based on an increasing number of sensing units. Because of the enhanced chemical reactivity of nanomaterials at lower temperatures, it seemed "natural" to investigate if nanoMOX could exhibit equal, or improved, sensing behaviors than their classical macroanalogues, but for minor energy expense.

During recent years several MOX-based nanosensors have been investigated. In 2002 Law et al. fabricated 


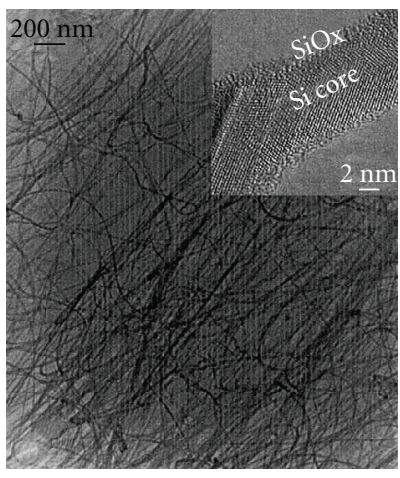

(a)

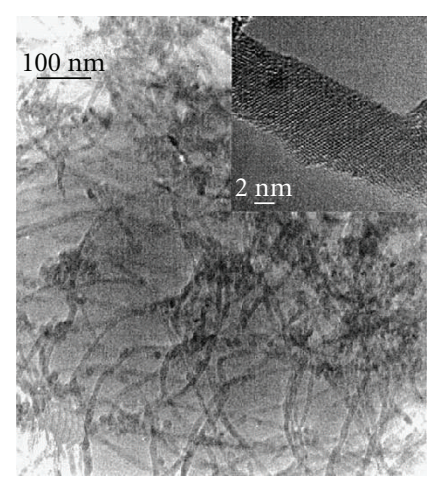

(b)

FIGURE 6: Silicon nanowire-based gas sensor. Transmission electron micrographs (TEM) of (a) nonetched and (b) HF-etched Si nanowires. The insets show the high-resolution TEM. (Reprinted from [90], copyright (2003) with permission from Elsevier.)

TABLE 2: Chemical families detected with porous silicon-based chemical sensors (adapted from [53]).

\begin{tabular}{lcccc}
\hline Chemical family & Electrical & Optical & Other & References \\
\hline Alcohols & $\mathrm{x}$ & $\mathrm{x}$ & $\mathrm{x}$ & {$[54-62]$} \\
Ketons & $\mathrm{x}$ & $\mathrm{x}$ & $\mathrm{x}$ & {$[55,61,63]$} \\
Alkanes & & & $\mathrm{x}$ & {$[64-68]$} \\
Hal. Aliphatic & $\mathrm{x}$ & & & {$[63,69,70]$} \\
Ethers & & & $\mathrm{x}$ & {$[63]$} \\
Carboxylic acid & $\mathrm{x}$ & $\mathrm{x}$ & $\mathrm{x}$ & {$[63,71]$} \\
Cicloaliphatic & $\mathrm{x}$ & & & {$[63]$} \\
Aromatic & $\mathrm{x}$ & $\mathrm{x}$ & $\mathrm{x}$ & {$[55,61,63,72]$} \\
Halog. Aromatic. & $\mathrm{x}$ & & & {$[73]$} \\
Inorganic & $\mathrm{x}$ & $\mathrm{x}$ & $\mathrm{x}$ & {$[54-56,68,73-79]$} \\
Halogens & & $\mathrm{x}$ & & {$[49]$} \\
\hline
\end{tabular}

and tested the performance of individual $\mathrm{SnO}_{2}$ singlecrystal nanoribbons configured as four-probe conductometric chemical sensors. They found a detection limit for $\mathrm{NO}_{2}$ of 3 ppm with response/recovery times of the order of seconds. The change in the electrical conductivity was observable even near RT and was modulated by molecular adsorption on surface states assisted by ultraviolet (UV) light with an energy near the $\mathrm{SnO}_{2}$ bandgap [94].

Comini et al. deposited $\mathrm{SnO}_{2}$ nanobelts on Platinum interdigitated electrodes and investigated their behavior in the range $300^{\circ} \mathrm{C}-400^{\circ} \mathrm{C}$. The device showed excellent sensitivity towards $\mathrm{CO}$, ethanol, and $\mathrm{NO}_{2}$ which could be detected down to only a few ppbs. While $\mathrm{CO}$ and ethanol adsorption resulted in an increase in the conductivity, $\mathrm{NO}_{2}$ increased the nanobelts electrical resistivity [95]. Because of the macroscopic dimensions, the suggested operating mechanism was assumed similar to the classical, possibly improved by the higher S/V ratio [93].

Kolmakov et al. used nanoporous alumina as a template for synthesizing arrays of parallel Sn nanowires, which were converted to polycrystalline $\mathrm{SnO}_{2}$ nanowires of controlled composition and size. Conductance measurements on the individual nanowires were carried out in inert, oxidizing, and reducing environments in the temperature range $25^{\circ} \mathrm{C}-$ $300^{\circ} \mathrm{C}$. Configured as a $\mathrm{CO}$ sensor, a detection limit of a hundreds of ppms in dry air at $300^{\circ} \mathrm{C}$ was measured with a sensor response time of 30 seconds. The effect was ascribed to the $\mathrm{CO}$ reacting with preadsorbed oxygen species to form carbon dioxide, reducing the steady-state surface oxygen concentration and donating electrons into the bulk, with a subsequent conductivity increase [96].

Neri et al. fabricated $\mathrm{SnO}_{2}$ powders, annealed at $600^{\circ} \mathrm{C}$, that showed good sensitivity to low concentrations of ethanol (50 ppm-200 ppm). A remarkable enhancement of the sensitivity towards $\mathrm{C}_{2} \mathrm{H}_{5} \mathrm{OH}$, as well as response and recovery time, was observed by the addition of $1 \mathrm{wt} \% \mathrm{Pt}$. $\mathrm{Pt}$ enhances the adsorption and dissociation of molecular oxygen on semiconductor surfaces due to its peculiar catalytic properties. The surface species trap electrons from the metal oxide conduction band, increasing the resistance of the doped sample [97].

In Figure 7 a hydrogen sensor fabricated by Fields et al. from single $\mathrm{SnO}_{2}$ nanobelts, synthesized via catalyst-free thermal evaporation is shown. The sensitivity and response time of the sensors without any catalyst on the surface to $2 \%$ hydrogen at temperatures between $25^{\circ} \mathrm{C}$ and $80^{\circ} \mathrm{C}$ were measured. A sensitivity higher than $0.3 /\left(\% \mathrm{H}_{2}\right)$, with a response time of about 220 seconds and power consumption of only $10 \mathrm{nW}$ at room temperature, was demonstrated [98].

Chen et al. observed that $\mathrm{SnO}_{2}-\mathrm{In}_{2} \mathrm{O}_{3}$ nanocomposites exhibited high responsivity and selectivity towards $\mathrm{CO}$ and $\mathrm{NO}_{x}$, with a sensitivity depending on the composition and calcination temperature of the composites and on the device operating temperature. Sensing performance was further improved through the introduction of a small amount of metals or other oxides as dopants and surface coatings [99].

Similarly, $\mathrm{SnO}_{2} / \mathrm{Fe}_{2} \mathrm{O}_{3}$ nanocomposites have been used to realize an ethanol gas sensor (10 ppm-200 ppm), operating in the temperature range $150^{\circ} \mathrm{C}-450^{\circ} \mathrm{C}$. Different sensor performances could be obtained by balancing the $\mathrm{SnO}_{2} / \mathrm{Fe}_{2} \mathrm{O}_{3}$ content. The gas sensing mechanism is, in both cases, similar; the adsorbed air oxygen reacts with the excess electrons in the nanocomposite to give chemisorbed oxygen anions that react with a reducing gas (e.g., CO) [100]. 


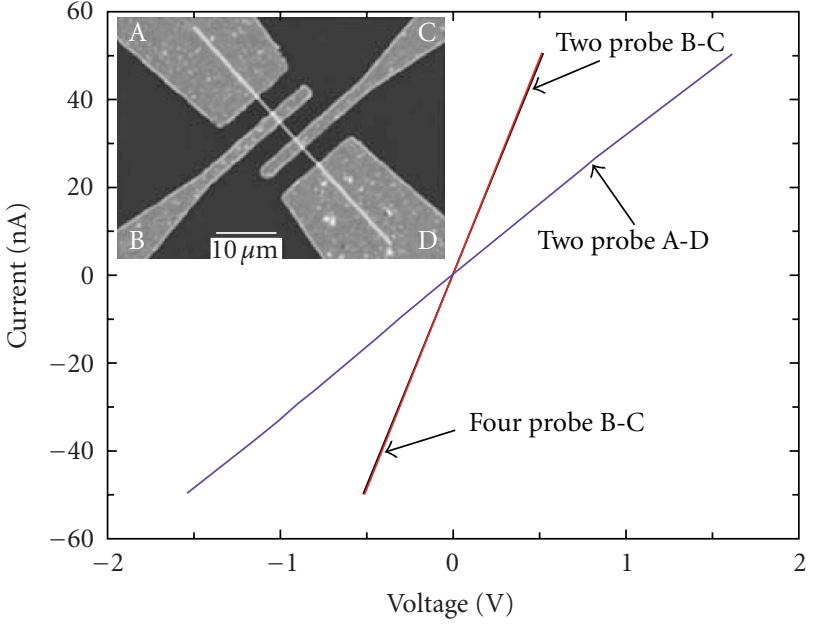

Figure 7: Hydrogen sensors based on single $\mathrm{SnO}_{2}$ nanobelts synthesized via catalyst-free thermal evaporation. Scanning electron microscopy image of the device and its electrical behavior in 2 and 4 probe configurations. (Reprinted from [98], copyright 2006, with permission from American Institute of Physics.)

$\mathrm{SnO}_{2} / \mathrm{MoO}_{3}$ nanocomposites have shown a response to alcohols, $\mathrm{C}_{n} \mathrm{H}_{2 n+n} \mathrm{OH}(n=1-4)$, and $\mathrm{NH}_{3}$, explained in terms of the acid-base scheme: Mo atoms at the $\mathrm{SnO}_{2}$ surface change the surface acidity and, in turn, its reactivity towards alcohols and ammonia or amine groups [101].

A humidity detector was realized using a single $\mathrm{SnO}_{2}$ nanowire as the sensing unit in a two-probe configuration. This sensor, shown in Figure 8, exhibited a fast and fairly high response to relative humidity $(\mathrm{RH})$ in air. The proposed operating mechanism was based on a model where physisorbed water molecules, reacting with the Lewis acid site ( $\mathrm{Sn}$ ) and Lewis base site (O) on the $\mathrm{SnO}_{2}$ surface to form $\left(\mathrm{Sn}_{\mathrm{Sn}}{ }^{+}-\mathrm{OH}^{-}\right)$complexes, released electrons. As a result, the depletion layer becomes thinner and increases the surface conductivity of the $\mathrm{SnO}_{2}$ nanowire [102].

A similar architecture, but in a 4-probe configuration, was also investigated by Mangkorntong and Thepnurat who reported on a single $\mathrm{SnO}_{2}$ nanowire-based sensor, shown in Figure 9 with a good room temperature sensitivity towards ethanol (1000 ppm) [103].

Shen et al. distributed $\mathrm{PdO}$ particles randomly on the surface of $\mathrm{SnO}_{2}$ nanowire testing sensors based on both undoped and Pd-doped $\mathrm{SnO}_{2}$ nanowires. The devices showed a reversible response to $\mathrm{H}_{2}$ at room temperature, with a response increasing for increasing Pd concentration [104]. Sensitivity improvement towards oxidizing and reducing gases in single, quasi-1D, chemiresistors (i.e., tin oxide nanowires or nanobelts) was similarly demonstrated by Kolmakov et al., after surface decoration with noble metal catalyst particles [105].

Recently, branched nanostructures have attracted great interest because they can provide means for improving parallel connectivity, enhancing device performance. For example, Wan et al. synthesized branched semiconducting

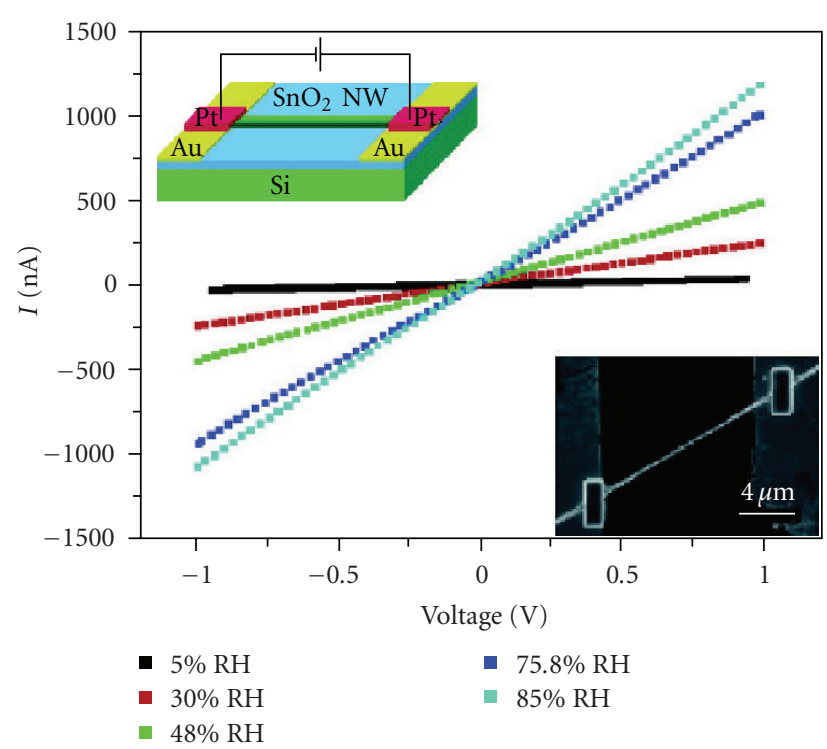

FIGURE 8: Humidity detector realized using a single $\mathrm{SnO}_{2}$ nanowire as the sensing unit in a 2-probe configuration. SEM image of a single $\mathrm{SnO} 2 \mathrm{NW}$ placed between two Au electrodes. Here the two Pt boxes have been deposited by Focused Ion Beam. (Reprinted from [102], copyright 2007, with permission from American Chemical Society.)

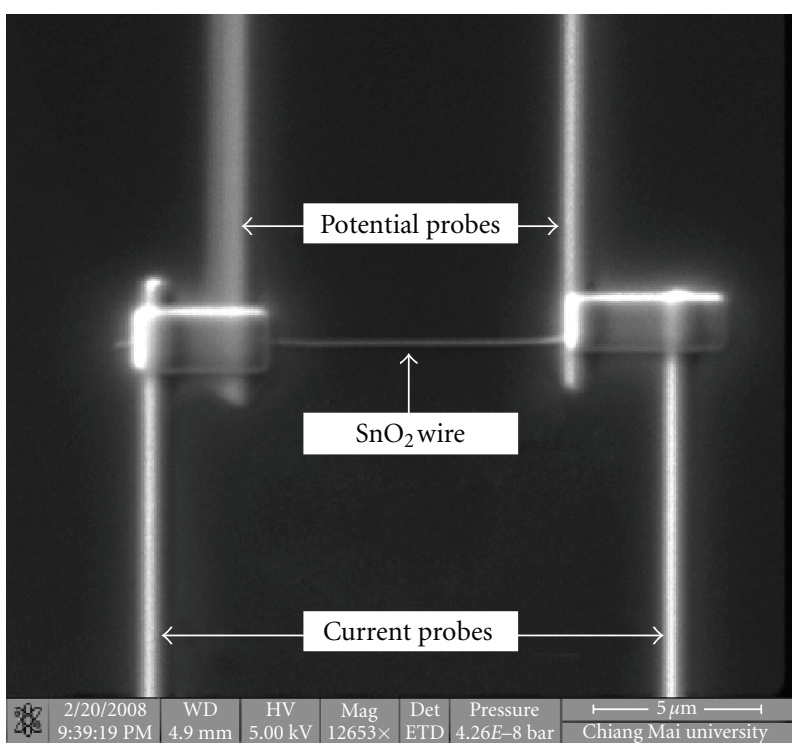

Figure 9: Ethanol nanosensor realized using a single $\mathrm{SnO}_{2}$ nanowire as the sensing unit in a 4-probe configuration. (Reprinted from [103], copyright 2008, with permission from the authors.)

$\mathrm{SnO}_{2}$ nanowires to realize a chemical nanosensor with excellent sensing characteristics for ethanol [106].

In 2004 Wang et al. fabricated individual $\mathrm{ZnO}$ nanowire transistors that exhibited high sensitivity to oxygen. The sensing properties of the chemical nanosensor, investigated using UV irradiation, were related to the trapping and releasing of carriers in the wires. Next year, the same research group fabricated sensors sensitive towards ethanol based on multipod-shaped, large surface area $\mathrm{ZnO}$ nanorods, having 
more than four up to tens of needle-like nanorods united at a common junction. With such a technology, they realized a sensor, shown in Figure 10 capable to detect $10 \mathrm{ppm}$ hydrogen at room temperature, with a rapid recovery [107109].

In 2007, vertically aligned $\mathrm{ZnO}$ nanowire arrays were grown on a langasite substrate by Cheng et al. The gas sensor device showed good sensing properties for $\mathrm{NO}_{2}$ [110].

Tang et al. realized a selective $\mathrm{NH}_{3}$ gas sensor based on a $\mathrm{Fe}_{2} \mathrm{O}_{3}-\mathrm{ZnO}$ nanocomposite, operating at room temperature. The increased sensitivity and selectivity to $\mathrm{NH}_{3}$ was attributed to the addition of $\mathrm{Fe}_{2} \mathrm{O}_{3}$ nanoparticles, which promotes the adsorption of $\mathrm{NH}_{3}$ molecules on the oxide surface and accelerates the oxidizing process [111].

However, the standard technique to enhance sensitivity and selectivity is the use of $\mathrm{Pt}, \mathrm{Au}$, or $\mathrm{Cu}$ catalysts. Wongka et al., for example, impregnated zinc oxide nanowires with platinum and gold nanoparticles to realize an ethanol sensor operating up to a concentration of $100 \mathrm{ppm}$ and at working temperature of $180^{\circ} \mathrm{C}-300^{\circ} \mathrm{C}$. An enhancement of sensitivity and recovery time was observed for ethanol sensor based on zinc oxide nanowires impregnated with platinum, but no enhancement was observed for zinc oxide nanowire impregnated with gold nanoparticles [112].

Similarly, Comini et al. investigated zinc oxide nanowire networks using an evaporation/condensation technique with uniform copper addition. $\mathrm{Cu}$ increased the sensor response to acetone, ethanol, $\mathrm{NO}_{2}$, and $\mathrm{CO}$ gases at $400^{\circ} \mathrm{C}$ [113]. Finally, transistors based on both single and multiple $\mathrm{In}_{2} \mathrm{O}_{3}$ nanowires operating at room temperature have been shown to detect $\mathrm{NO}_{2}$ down to ppb levels. The nanowires conductance was observed to decrease with increasing gas concentration [114].

In Table 3 an overview of the above results for $\mathrm{SnO}_{2}$ nanosensors is given. Sensor response is generally high and recovery rather fast, in spite of the often ambient temperature operating conditions. It should be noted that, as for the previous cases, some sort of conditioning process was often undertaken.

3.4. Metal Nanosensors. Most of the papers related to this topic discuss nanosensor devices based on nanowires. The reason being that metal nanowires have features such as strength, ductility, and chemical stability, that make them attractive candidates for device processing. Furthermore, when the diameter of these structures is in the nanorange, they could represent interesting transducers since the S/V ratio increases with the inverse of the wire diameter. However, the basic operating mechanism for this class of sensors is strictly related to innate metal characteristics. For example, $\mathrm{H}_{2}$ nanosensors based on $\mathrm{Pd}$ nanowires work by virtue of a change in the $\mathrm{Pd}$ crystalline phase upon exposure to low concentrations of $\mathrm{H}_{2}$ and/or by means of surface conversion into the more insulating $\mathrm{PdH}_{2}$ after $\mathrm{H}_{2}$ interaction [115117].

Walter et al. realized different metal nanowires using the electrochemical step-edge decoration technique (ESED) and characterized them as chemical sensors. Depending essentially on the kinetics of the reduction reaction, two different ways of preparing metal nanowires have been developed. For metal cations with a slow transfer rate, as Molybdenum or Cadmium, metal oxide wires $\left(\mathrm{MoO}_{x}\right.$ and $\mathrm{Cd}(\mathrm{OH})_{2}$, resp.) were electrodeposited from aqueous solutions. The resulting wires were converted into pure metal wires by reduction with $\mathrm{H}_{2}$, or with $\mathrm{H}_{2} \mathrm{~S}$, at high temperature. In contrast, from acidic solutions of palladium, gold, silver, and copper, no oxide formation is observed and nanowires are obtained as pure metals by electrodeposition [115]. Conductive gas sensors based on silver and palladium nanowires were fabricated. Ag nanowires, with diameters ranging from $150 \mathrm{~nm}$ to $950 \mathrm{~nm}$ and lengths up to $100 \mu \mathrm{m}$, upon exposure to ammonia vapor showed an increase in electrical resistance (up to $10000 \%$ ) that was fast ( $<5$ seconds) and reversible. The same reversible behavior, although characterized by a slower response time (1 minute), was recorded in the presence of liquid amine vapor, while an irreversible resistance increase was found when they were exposed to hydrogen sulfide. Conversely, carbon monoxide, oxygen, hydrocarbons, argon, and water caused no change in resistance for exposures up to 10 seconds [118].

Arrays of palladium nanowires were investigated as $\mathrm{H}_{2}$ sensors [115-117]. Macroscopic Pd-based hydrogen sensors suffer from two major drawbacks: response times that span from 0.5 second to several minutes, which is too slow to monitor gas in real-time conditions, and the fact that a number of gas molecules, such as methane, oxygen, and carbon monoxide adsorb onto the sensor surfaces and block the adsorption sites for hydrogen molecules. Pd nanowire hydrogen sensors offer solutions to the above problems. They have a large surface-to-volume ratio and are characterized by the presence of small (nano)gaps that the $\mathrm{H}_{2}$ induced Pd swelling tends to close, as shown in Figure 11 The result is a response time that can be as fast as 20 milliseconds, when devices are characterized at high $\mathrm{H}_{2}$ concentrations ( $>8 \%$ ), and devices that seem to be less subject to poisoning by common contaminants. Hydrogen exposure produced a strong increase in the electrical current as investigated by Favier and coworkers [116, 117]. Nanowires consist of agglomerated Pd grains with "intergrain" nanogaps. When exposed to hydrogen, the gas diffuses into the lattice and reacts with the metal forming a metal hydride ( $\mathrm{PdHx}$ ), resulting in a volumetric wire expansion with a partial or total closure of the gaps. A strong increase in the electrical conductivity can then be observed. Grain swelling is not completely reversible: after $\mathrm{H}_{2}$ removal, the grains come back to the initial volume but not to the initial position.

Palladium mesowires and nanowires can be fabricated by electrodeposition from aqueous solutions of $\mathrm{Pd}^{2+}$ onto step edges naturally present on highly oriented pyrolitic graphite surfaces. Freshly deposited Pd nanowires are then detached from the graphite and transferred onto a glass substrate by means of cyanoacrylate.

Another technique, which simplifies the previous one by avoiding the use of a template, is to directly manufacture a Pd nanowire array onto a crystalline silicon substrate. The choice of a silicon substrate opens the way to the direct integration of this kind of sensor device in microelectronics. $\mathrm{Pd}$ nanowire arrays were actually assembled directly onto a 

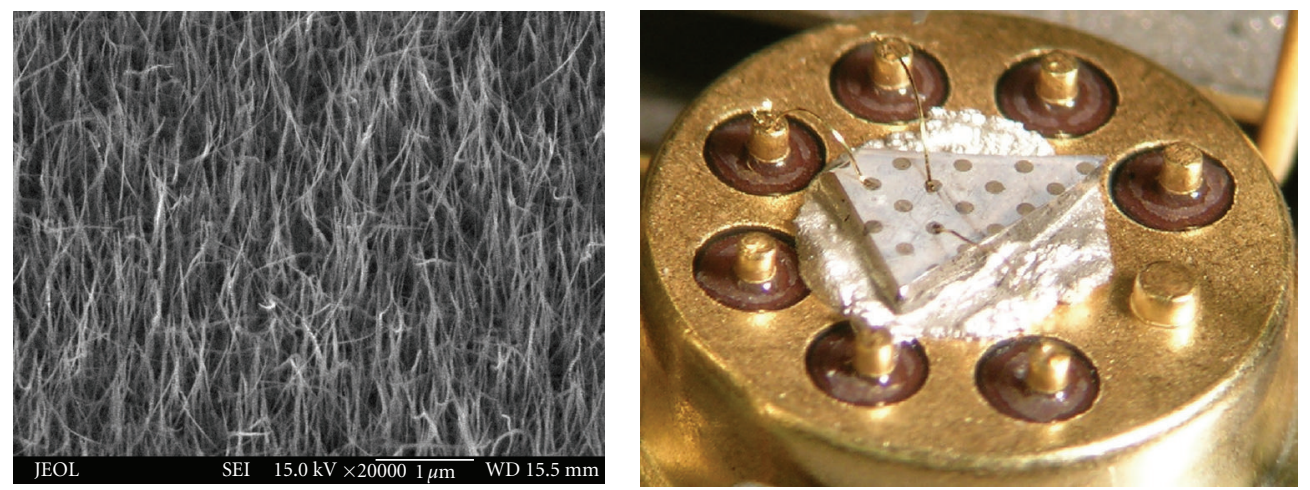

FiguRE 10: $\mathrm{H}_{2}$ nanosensor based on $\mathrm{ZnO}$ nanorods. SEM of $\mathrm{ZnO}$ multiple nanorods (left), and photograph of the nanorods contacted by $\mathrm{Al} / \mathrm{Pt} / \mathrm{Au}$ electrodes (right). The $\mathrm{ZnO}$ chip has edge length $\sim 5 \mathrm{~mm}$ in the left photo. (Reprinted from [109], copyright 2005, with permission from American Institute of Physics.)

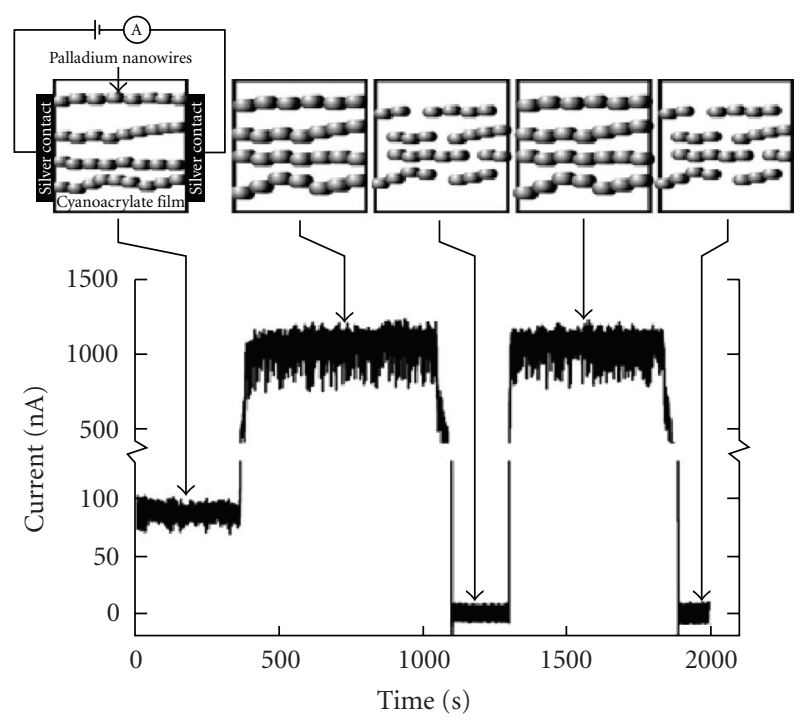

Figure 11: $\mathrm{H}_{2}$ Pd nanowire hydrogen sensors are characterized by a strong response in less than 20 milliseconds. Shown at top is the mechanism proposed for sensor operation. (Reprinted from [116], copyright 2001, with permission from the American Association for the Advancement of Science.)

silicon chip, by means of AC dielectrophoresis using a metal salt solution as a feed material. It was showed that nanowire morphology affects the electrical conductivity when devices are exposed to up to $4 \%$ of hydrogen, in nitrogen carrier, at room temperature. It was found that thinner nanowires (less than $90 \mathrm{~nm}$ wide) responded faster than thicker ones, with up to $140 \%$ current changes in the presence of $4 \% \mathrm{H}_{2}[119,120]$.

\section{Discussion and Conclusions}

In the above sections we reported on almost one hundred sensor devices based on different nanomaterials. It is worth noting, however, that none of these has yet emerged as commercially valuable. In this section, this point is discussed in order to understand the existence of possible technological constraints intrinsically limiting the development of saleable gas nanosensors.

First of all, let us observe that gas nanosensor fabrication technology is far from being assessed for either the sensitive film and the transducer. In Table 4 gas nanosensors reviewed in this work have been classified according to their transduction mechanism. Although all the most common gas sensor architectures are considered, optical and electrically conductive devices (including FETs) are the most frequently investigated.

Nanosensor device processing requires at least two distinct steps: (1) sensitive nanomaterial production and selection, and (2) placing the sensitive nanomaterial on prepatterned electrodes, sometimes followed by an NP alignment procedure.

With respect to the first step, Table 5 presents an overview of the different fabrication processes used for the sensitive element for each gas nanosensors type. Although several processes, both "top-down" and "bottom-up" have actually been exploited to fabricate the sensitive material, it appears that chemical-based techniques, probably by virtue of their flexibility, are favoured.

At present it is the second step, that is the ability to connect the micro-(nano) world to the macro-one, creating functional heterostructures and interfaces between the nanomaterial and the electrodes, that seems to be the most critical one. This is probably true not only for nanosensors but for any nanodevice. Actually, most of the reported gas nanosensor transducers are fabricated using standard electronic processing techniques and only in a few cases have specific nanotools, such as the Focused Ion Beam, been employed (although mainly as nano-soldering equipment). However, any technological process on a nanomaterial needs to be set up in such a way as to prevent nanomaterial deterioration with manipulation and to preserve the properties of the nanostate.

In this respect several different approaches have been discussed, mainly following two different strategies: (1) the deposition of the nanomaterial in the form of a dispersion on a prepatterned substrate, and (2) the formation of contacting electrodes onto the deposition itself. 
TABLE 3: A summary of $\mathrm{SnO}_{2}$ based nanosensor properties and performances. Sensors generally show high responses and often work at RT. In several cases, some sort of conditioning process is adopted to improve device characteristics.

\begin{tabular}{|c|c|c|c|c|c|c|}
\hline Material & $\begin{array}{l}\text { Chemical species } \\
\text { (carrier) }\end{array}$ & Range & Recovery & Conditioning & notes & Ref. \\
\hline $\mathrm{SnO}_{2}$ nanoribbons & $\begin{array}{l}\mathrm{NO}_{2} \\
\text { (synthetic air) }\end{array}$ & $3 \mathrm{ppm}$ & $\begin{array}{l}\text { Yes, few seconds } \\
\text { by UV irradiation }\end{array}$ & Yes & $\begin{array}{l}\text { Reversible at RT. } \\
\text { Photoinduced desorption } \\
\text { of the analyte }\end{array}$ & [94] \\
\hline $\mathrm{SnO}_{2}$ nanobelts & $\begin{array}{l}\mathrm{NO}_{2} \\
\text { (synthetic air) }\end{array}$ & few ppb & Yes & Yes & $\begin{array}{l}\text { Operating temperature is } \\
400^{\circ} \mathrm{C} . \mathrm{CO} \text { and ethanol } \\
\text { increase the conductivity, } \\
\text { while } \mathrm{NO}_{2} \text { decreases the } \\
\text { conductivity, of the } \mathrm{SnO}_{2} \\
\text { nanobelts }\end{array}$ & {$[95]$} \\
\hline $\mathrm{SnO}_{2}$ nanowires & CO (dry air) & few hd ppm & Yes & Yes & $\begin{array}{l}\text { CO increases the } \\
\text { conductivity with response } \\
\text { times of } \sim 30 \text { s at } 300^{\circ} \mathrm{C}\end{array}$ & {$[96]$} \\
\hline $\mathrm{SnO}_{2}$ nanopowders & $\mathrm{C}_{2} \mathrm{H}_{5} \mathrm{OH}$ ( air) & $50-200 \mathrm{ppm}$ & Yes & Yes & Annealing at $600^{\circ} \mathrm{C}$ & {$[97]$} \\
\hline $\begin{array}{l}\text { Single } \mathrm{SnO}_{2} \\
\text { nanobelts }\end{array}$ & $\mathrm{H}_{2}$ & $2 \% \mathrm{H}_{2}$ & Yes & Yes & $\begin{array}{l}\text { Operating temperatures } \\
\text { between } 25^{\circ} \mathrm{C} \text { and } 80^{\circ} \mathrm{C} \text {. } \\
\text { Resistance decreases with } \\
\text { response time }<220 \mathrm{~s} \text {; } \\
\text { power cons. }<10 \mathrm{nW} @ \\
25^{\circ} \mathrm{C}\end{array}$ & [98] \\
\hline $\begin{array}{l}\mathrm{SnO}_{2}-\mathrm{In}_{2} \mathrm{O}_{3} \\
\text { nanocomposite } \\
\text { oxides }\end{array}$ & $\begin{array}{l}\mathrm{CO} \text { (air) } \\
\mathrm{NO}_{2} \text { (air) }\end{array}$ & $\begin{array}{l}\text { Sensitivity of } 16.0 \text { and } \\
7.5 \text { to } \mathrm{CO} \text { and } \mathrm{NO}_{2} \text {, } \\
\text { respectively }\end{array}$ & NA & Yes & $\begin{array}{l}\text { Nanocomposites calcined } \\
\text { at } 600^{\circ} \mathrm{C} \text {. Sensitivity } \\
\text { increases with gas } \\
\text { concentration at } \\
100^{\circ} \mathrm{C}-300^{\circ} \mathrm{C}\end{array}$ & [99] \\
\hline $\begin{array}{l}\mathrm{SnO}_{2} / \mathrm{Fe}_{2} \mathrm{O}_{3} \\
\text { nanocomposites }\end{array}$ & $\begin{array}{l}\mathrm{CO} \\
\text { ethanol } \\
\mathrm{H}_{2} \mathrm{~S} \mathrm{NO}_{2} \\
(\mathrm{RH} 30 \%)\end{array}$ & $\begin{array}{l}\mathrm{CO}(40-150 \mathrm{ppm}), \\
\text { ethanol }(10-200 \mathrm{ppm}) \text {, } \\
\mathrm{H}_{2} \mathrm{~S}(2-10 \mathrm{ppm}) \\
\mathrm{NO}_{2}(50 \mathrm{ppb}-10 \mathrm{ppm})\end{array}$ & NA & Yes & $\begin{array}{l}\text { Temperature range: } \\
150^{\circ} \mathrm{C}-450^{\circ} \mathrm{C} \text {. Increasing of } \\
\mathrm{Fe}_{2} \mathrm{O}_{3} \text { content results in } \\
\text { oxidation enhancement. }\end{array}$ & [100] \\
\hline $\begin{array}{l}\mathrm{SnO}_{2} / \mathrm{MoO}_{3} \\
\text { nanostructure }\end{array}$ & $\begin{array}{l}\mathrm{C}_{n} \mathrm{H}_{2 n+1} \mathrm{OH} \\
(n=1-4) ; \\
\mathrm{NH}_{3} \text { in air }\end{array}$ & $\begin{array}{l}1 \mu \mathrm{l} \text { alcohols }\left(300^{\circ} \mathrm{C}\right) \\
500 \text { ppm } \mathrm{NH}_{3}\left(350^{\circ} \mathrm{C}\right)\end{array}$ & NA & Yes & $\begin{array}{l}\text { Electric sensor response to } \\
\text { the alcohols decreases with } \\
\text { increasing } \mathrm{MoO}_{3} \text { content }\end{array}$ & {$[101]$} \\
\hline $\begin{array}{l}\text { single } \mathrm{SnO}_{2} \\
\text { nanowire }\end{array}$ & $\mathrm{RH}$ & $5 \%-85 \%$ RH & Yes & Yes & $\begin{array}{l}\text { Pt boxes deposited by } \\
\text { focused ion beam (FIB) } \\
\text { improve electrode contact. } \\
\mathrm{R} \text { decreases with the } \\
\text { increase of } \mathrm{RH} \text { in air at } \\
30^{\circ} \mathrm{C}\end{array}$ & {$[102]$} \\
\hline
\end{tabular}

TABLE 4: Nanosensor architectures.

\begin{tabular}{|c|c|c|c|c|c|}
\hline Sensor type & CNT & Nanosilicon & Nano-MOX & Nanometal & References \\
\hline Optical & $\mathrm{x}$ & $\mathrm{x}$ & $\mathrm{x}$ & & {$[51,56-58,60,62,64,65,67,70-74,76,79,86-89,121,122]$} \\
\hline Conductive & $\mathrm{x}$ & $\mathrm{x}$ & $\mathrm{x}$ & $\mathrm{x}$ & $\begin{array}{l}{[29,30,32-36,39-47,54,59,61,63,66,68,75-78,80-85,90,91,94-} \\
101,103-106,108,109,111-113,115-120]\end{array}$ \\
\hline QMB & $\mathrm{x}$ & & & & {$[121,123]$} \\
\hline MEMS & $\mathrm{x}$ & & $\mathrm{x}$ & & {$[124-126]$} \\
\hline SAW & $\mathrm{x}$ & & $\mathrm{x}$ & & {$[110,127,128]$} \\
\hline FET & $\mathrm{x}$ & $\mathrm{x}$ & $\mathrm{x}$ & & {$[37,38,92,102,107,114,122,129-133]$} \\
\hline
\end{tabular}


TABLE 5: The different nanomaterial fabrication processes used for gas nanosensor sensitive layer fabrication.

\begin{tabular}{|c|c|c|c|c|c|}
\hline $\begin{array}{l}\text { Sensitive layer } \\
\text { processing technique }\end{array}$ & CNT & Nanosilicon & Nano-MOX & Nanometal & References \\
\hline Commercial material & $\mathrm{x}$ & & $\mathrm{x}$ & & {$[33,34,38-40,44-47,121,123,127,128,131]$} \\
\hline Electrochemical & & $\mathrm{x}$ & $\mathrm{x}$ & & {$[51,54,56-58,60,61,63-67,70-87,89,96,133]$} \\
\hline Chemical & & & $\mathrm{x}$ & & {$[91,97,99-101,110,111,126,134]$} \\
\hline $\begin{array}{l}\text { Electro/dielectro- } \\
\text { phoresis }\end{array}$ & & & & $\mathrm{x}$ & {$[115-120]$} \\
\hline $\mathrm{MBE}$ & & & $\mathrm{x}$ & & {$[109,135]$} \\
\hline Thermal evaporation & & & $\mathrm{x}$ & & {$[94,95,98,104,107,122,130]$} \\
\hline Pyrolysis & $\mathrm{x}$ & & & & {$[41,43]$} \\
\hline Microwave & & & $\mathrm{x}$ & & {$[42,68]$} \\
\hline CVD-VLS & $\mathrm{x}$ & & & & {$[35,88,102,124,129,132]$} \\
\hline HiPco & $\mathrm{x}$ & & & & {$[32]$} \\
\hline Laser ablation & $\mathrm{x}$ & & $\mathrm{x}$ & & {$[30,31,114]$} \\
\hline
\end{tabular}

TABle 6: Classification of the reviewed papers according to the different technological strategies followed for gas nanosensor device fabrication.

\begin{tabular}{|c|c|}
\hline $\begin{array}{l}\text { Gas nanosensor technological } \\
\text { process }\end{array}$ & References \\
\hline $\begin{array}{l}\text { (1) Deposition of the } \\
\text { nanomaterial in the form of a } \\
\text { dispersion on a prepatterned } \\
\text { substrate. }\end{array}$ & $\begin{array}{l}{[32,38-42,45,68,82,94,95,} \\
97,100,104,107,111,118,121- \\
123,127-132,134]\end{array}$ \\
\hline $\begin{array}{l}\text { (2) Nanomaterial, in the form } \\
\text { of a dispersion, is deposited on } \\
\text { the substrate and contacting } \\
\text { electrodes are realized onto the } \\
\text { nanomaterial. }\end{array}$ & $\begin{array}{l}{[54,61,63,75,76,78,80,81,} \\
84,85,88,91,96,98,99,102, \\
106,109,114,126]\end{array}$ \\
\hline $\begin{array}{l}\text { (3) "Growth in place": the } \\
\text { fabrication of the nanomaterial } \\
\text { is performed exactly where the } \\
\text { nanodevice architecture } \\
\text { requires it, exploiting existing } \\
\text { electrodes. }\end{array}$ & {$[35,46,110,119,120,124,133]$} \\
\hline Others (mainly optical) & $\begin{array}{l}{[51,56-58,60,65-67,70-} \\
74,79,87,89]\end{array}$ \\
\hline
\end{tabular}

In the former case, nanomaterial is prepared in the form of a dispersion which is then deposited by some suitable technique (spin-coating, printing, dip coating, etc.) onto a prepatterned transducer (generally fabricated using standard electronic techniques). A postannealing is often exploited to improve the contact characteristics. This approach nominally preserves the nanomaterial characteristics and allows, to some degree, its alignment when electrochemical techniques are adopted. However dispersions are very rarely characterized in terms of particle size, polydispersion index, solvent/solute interaction, and so forth so that the results reported suffer from poor reproducibility. Moreover, the quality of the contact nanomaterial/electrode is rarely investigated. Annealing treatments are quite regularly adopted, often on a purely empirical basis, both to free the dispersion from its solvent and to improve the electric contact characteristics, but their effectiveness is not clear.

In the latter case the nanomaterial, in the form of a dispersion, is deposited on the substrate and contacting electrodes are deposited onto the nanomaterial itself using standard techniques (thermal or e-beam evaporation, sputtering, etc.) or even using silver paint. Again, a postannealing is often exploited to improve the contact characteristics. Devices based on single nanoparticles "captured" from random dispersions and contacted with this technique have been investigated.

It is worth noting that since the first approach does not require any further nanomaterial treatment, it is generally considered the most suitable to preserve nanomaterial physical properties.

Actually, a third approach exists, although discussed in an only limited number of papers. It is the so-called "growth in place" technique that allows fabrication of the nanomaterial exactly where the nanodevice architecture requires it, strongly simplifying the process and avoiding excessive handling of the nanomaterial $[136,137]$.

In Table 6 papers reviewed have been classified according to the different technological strategies followed for gas nanosensor fabrication.

Apart from a few notable exceptions, mainly observed in silicon-based nanosensors, none of the reported devices seem to operate by exploiting quantum effects; nanomaterial characteristic dimensions are still too far from the Bohr exciton radius for quantum properties to become apparent. In spite of this, different proposed nanosensors show enhanced reactivities towards a wide range of analytes and are characterized by fairly high sensitivities at an operating temperature which is very often near room temperature. This effect has been attributed to the combination of an improved $\mathrm{S} / \mathrm{V}$ ratio and the presence of surface defects that strongly link the electrical conductance of the device to the nanomaterial environment.

Although in a few cases no recovery at all could be observed, in many devices the response and recovery times could be measured in the range from seconds to several tens 
of minutes. This should not be surprising since the operating temperature is often the ambient temperature, but it is actually one of the most serious limitations to nanosensor applications. Procedures to improve response and recovery times have been suggested by various authors. Mechanical perturbations such as gas over- or underpressure, external heating, light illumination at various frequencies (from IR to UV), application of external electric fields, have been all exploited to improve device recovery and, in a few cases, also to enhance sensitivity. In most cases these treatments proved to be effective, but no theoretical background was proposed to account for their effect.

Selectivity is rarely an issue and it is at most pursued by using some kind of catalyst to accelerate a given reaction, mainly in the case of MOX nanosensors.

Finally, sensor conditioning (or training) is quite a common processing step. Since one of the main advantages of a nanosensor is its ability to operate at RT, conditioning cannot be performed by heating the sensor around the operating temperature, as happens in standard solid state chemical sensors with operating temperatures of hundreds of ${ }^{\circ} \mathrm{C}$. Several processes have been proposed involving prolonged soaking in the target analyte with or without, light illumination or mild heating. The effect has been shown to always be positive, mainly on the sensor baseline.

In summary, the gas nanosensors so far investigated have several problems, the most important being: (1) lack of reliable and well-assessed fabrication processes, (2) very long response and recovery times, and (3) quite unstable baselines. These factors remain important technological issues that prevent, at present, the development of saleable gas sensors made from nanomaterials. On the other hand, no technological constraint seems to intrinsically limit the development of seleable gas nanosensors.

The results we have discussed in fact show that the enhanced chemical reactivity of the nanostate can be effectively used to fabricate devices working at room temperature. However, since the fabrication process is itself under investigation, the proposed devices are often not reproducible and characterized by parameters whose meaning is limited by poor statistics. Moreover, the fabrication process often requires unconventional and expensive equipment so that economic requirements could further limit commercial development. An effort should be made to define standards both in nanomaterial characterization and in fabrication techniques. In this respect, recent "growth in place" approaches seem to be a very useful technological platform for nanosensor fabrication since such approaches can prevent nanomaterial deterioration with manipulation and preserve the properties of the nanostate.

\section{References}

[1] W. Gopel, "Nanostructured sensors for molecular recognition," Philosophical Transactions of the Royal Society of London A, vol. 353, p. 333, 1996.

[2] W. Gopel, "Chemical sensing, molecular electronics and nanotechnology: Interface technologies down to the molecular scale," Sensors and Actuators B, vol. 4, p. 1, 1991.
[3] Chemical AND nano* AND sensor*, 1998-2007, http:// apps.isiknowledge.com.

[4] Nanotechnology: Basic Information, http://es.epa.gov/ncer/ nano/questions/index.html.

[5] X.-J. Huang and Y.-K. Choi, "Chemical sensors based on nanostructured materials," Sensors and Actuators B: Chemical, vol. 122, p. 659, 2007.

[6] G. Jiménez-Cadena, J. Riu, and F. X. Rius, "Gas sensors based on nanostructured materials," Analyst, vol. 132, no. 11, pp. 1083-1099, 2007.

[7] J. Riu, A. Maroto, and F. X. Rius, "Nanosensors in environmental analysis," Talanta, vol. 69, no. 2, pp. 288-301, 2006.

[8] A. P. Alivisatos, "Semiconductor clusters, nanocrystals, and quantum dots," Science, vol. 271, no. 5251, pp. 933-937, 1996.

[9] L. E. Brus, "A simple model for the ionization potential, electron affinity, and aqueous redox potentials of small semiconductor crystallites," The Journal of Chemical Physics, vol. 79, no. 11, pp. 5566-5571, 1983.

[10] M. Antonietti and C. Göltner, "Superstructures of functional colloids: chemistry on the nanometer scale," Angewandte Chemie International Edition, vol. 36, no. 9, pp. 910-928, 1997.

[11] M. Antonietti, K. Landfester, and Y. Mastai, "The vision of "nanochemistry", or is there a promise for specific chemical reactions in nano-restricted environments?" Israel Journal of Chemistry, vol. 41, no. 1, pp. 1-5, 2001.

[12] L. E. Brus, "Model for carrier dynamics and photoluminescence quenching in wet and dry porous silicon thin films," Physical Review B, vol. 15, no. 8, 1996.

[13] L. E. Brus, "Electron-electron and electron-hole interactions in small semiconductor crystallites: the size dependence of the lowest excited electronic state," The Journal of Chemical Physics, vol. 80, no. 9, pp. 4403-4409, 1984.

[14] G. Di Francia, L. Quercia, I. Rea, P. Maddalena, and S. Lettieri, "Nanostructure reactivity: confinement energy and charge transfer in porous silicon," Sensors and Actuators B: chemical, vol. 111-112, pp. 117-124, 2005.

[15] N. Sutin, "The Kinetics of Inorganic Reactions in Solution," Annual Review of Physical Chemistry, vol. 17, p. 119, 1966.

[16] R. A. Marcus, "Electron transfer reactions in chemistry. Theory and experiment," Reviews of Modern Physics, vol. 65, no. 3, pp. 599-610, 1993.

[17] G. M. Brown and N. Sutin, "A comparison of the rates of electron exchange reactions of ammine complexes of ruthenium(II) and -(III) with the predictions of adiabatic, outersphere electron transfer models," Journal of the American Chemical Society, vol. 101, no. 4, pp. 883-892, 1979.

[18] G. A. Zalesskaya, E. G. Sambor, and N. N. Bely, "Photoinduced gas-phase electron transfer reactions," Journal of Fluorescence, vol. 14, no. 2, pp. 173-180, 2004.

[19] D. K. Ferry and R. Akis, "Nonlocal effects in semiconductor nanostructure transport," Journal of Physics: Condensed Matter, vol. 20, no. 45, Article ID 454201, 2008.

[20] M. J. Sailor and E. J. Lee, "Surface chemistry of luminescent silicon nanocrystallites," Advanced Materials, vol. 9, no. 10, pp. 783-793, 1997.

[21] N. Yamazoe, "New approaches for improving semiconductor gas sensors," Sensors and Actuators B, vol. 5, no. 1-4, pp. 7-19, 1991.

[22] G. Di Francia, M. Della Noce, V. La Ferrara, L. Lancellotti, P. Morvillo, and L. Quercia, "Nanostructured porous silicon for gas sensor applications," Materials Science and Technology, vol. 18 , no. 7, pp. 767-771, 2002. 
[23] Z. Zhou, R. A. Friesner, and L. Brus, "Electronic structure of 1 to $2 \mathrm{~nm}$ diameter silicon core/shell nanocrystals: surface chemistry, optical spectra, charge transfer, and doping," Journal of the American Chemical Society, vol. 125, no. 50, pp. 15599-15607, 2003.

[24] R. Tang, C. A. Orme, and G. H. Nancollas, "Dissolution of crystallites: surface energetic control and size effects," ChemPhysChem, vol. 5, no. 5, pp. 688-696, 2004.

[25] A. W. Adamson and A. P. Gast, Physical Chemistry of Surfaces, John Wiley \& Sons, New York, NY, USA, 1997.

[26] R. K. Iler, The Chemistry of Silica: Solubility, Polymerization Colloid and Surface Properties and Biochemistry, John Wiley \& Sons, New York, NY, USA, 1979.

[27] H. Zhu and R. S. Averback, "Sintering processes of two nanoparticles: a study by moleculardynamics," Philosophical Magazine Letters, vol. 73, p. 27, 1997.

[28] B. K. Teo and X. H. Sun, "From top-down to bottom-up to hybrid nanotechnologies: road to nanodevices," Journal of Cluster Science, vol. 17, no. 4, pp. 529-540, 2006.

[29] J. Kong, N. R. Franklin, C. Zhou, et al., "Nanotube Molecular Wires as Chemical Sensors," Science, vol. 287, p. 5453, 2000.

[30] A. Zettl, "Extreme oxygen sensitivity of electronic properties of carbon nanotubes," Science, vol. 287, no. 5459, pp. 1801$1804,2000$.

[31] P. G. Collins, A. Zettl, H. Bando, A. Thess, and R. E. Smalley, "Nanotube nanodevice," Science, vol. 278, no. 5335, pp. 100103, 1997.

[32] J. Li, Y. Lu, Q. Ye, M. Cinke, J. Han, and M. Meyyappan, "Carbon nanotube sensors for gas and organic vapor detection," Nano Letters, vol. 3, no. 7, pp. 929-933, 2003.

[33] Y. Lu, J. Li, J. Han, H.-T. Ng, C. Binder, C. Partridge, and M. Meyyappan, "Room temperature methane detection using palladium loaded single-walled carbon nanotube sensors," Chemical Physics Letters, vol. 391, no. 4-6, pp. 344-348, 2004.

[34] L. Valentini, I. Armentano, L. Lozzi, S. Santucci, and J. M. Kenny, "Interaction of methane with carbon nanotube thin films: role of defects and oxygen adsorption," Materials Science and Engineering C, vol. 24, no. 4, pp. 527-533, 2004.

[35] W. Wongwiriyapan, S.-I. Honda, H. Konishi, et al., "Direct growth of single-walled carbon nanotube networks on alumina substrate: a novel route to ultrasensitive gas sensor fabrication," Japanese Journal of Applied Physics, vol. 44, no. 11, pp. 8227-8230, 2005.

[36] M. Penza, G. Cassano, R. Rossi, et al., "Effect of growth catalysts on gas sensitivity in carbon nanotube film based chemiresistive sensors," Applied Physics Letters, vol. 90, no. 10, Article ID 103101, 2007.

[37] N. H. Vedala, Y. C. Choi, X. Y. Zhou, G. Kim, and W. B. Choi, in Materials Research Society Symposium Proceedings, vol. 858E, Materials Research Society, 2005, HH13.22.1.

[38] M. Lucci, A. Reale, A. Di Carlo, S. Orlanducci, et al., "Optimization of a NOx gas sensor based on single walled carbon nanotubes," Sensors and actuators B: Chemical, vol. 118, no. 1-2, pp. 226-231, 2006.

[39] T. Zhang, M. B. Nix, B.-Y. Yoo, M. A. Deshusses, and N. V. Myung, "Electrochemically functionalized single-walled carbon nanotube gas sensor," Electroanalysis, vol. 18, no. 12, pp. 1153-1158, 2006.

[40] H.-Q. Nguyen and J.-S. Huh, "Behavior of single-walled carbon nanotube-based gas sensors at various temperatures of treatment and operation," Sensors and Actuators B, vol. 117, no. 2, pp. 426-430, 2006.

[41] Y.-L. Liu, H.-F. Yang, Y. Yang, Z.-M. Liu, G.-L. Shen, and R.$\mathrm{Q}$. Yu, "Gas sensing properties of tin dioxide coated onto multi-walled carbon nanotubes," Thin Solid Films, vol. 497, no. 1-2, pp. 355-360, 2006.

[42] S. K. Padigi, R. K. K. Reddy, and S. Prasad, "Carbon nanotube based aliphatic hydrocarbon sensor," Biosensors and Bioelectronics, vol. 22, no. 6, pp. 829-837, 2007.

[43] J. Suehiro, N. Sano, G. Zhou, H. Imakiire, K. Imasaka, and M. Hara, "Application of dielectrophoresis to fabrication of carbon nanohorn gas sensor," Journal of Electrostatics, vol. 64, no. 6, pp. 408-415, 2006.

[44] K. Lee, J.-W. Lee, K.-Y. Dong, and B.-K. Ju, "Gas sensing properties of single-wall carbon nanotubes dispersed with dimethylformamide," Sensors and Actuators B, vol. 135, no. 1, pp. 214-218, 2008.

[45] J. Suehiro, S.-I. Hidaka, S. Yamane, and K. Imasaka, "Fabrication of interfaces between carbon nanotubes and catalytic palladium using dielectrophoresis and its application to hydrogen gas sensor," Sensors and Actuators B, vol. 127, no. 2, pp. 505-511, 2007.

[46] M. L. Y. Sin, G. C. T. Chow, G. M. K. Wong, W. J. Li, P. H. W. Leong, and K. W. Wong, "Ultralow-power alcohol vapor sensors using chemically functionalized multiwalled carbon nanotubes," IEEE Transactions on Nanotechnology, vol. 6, no. 5, pp. 571-577, 2007.

[47] S. M. C. Vieira, P. Beecher, I. Haneef, et al., "Use of nanocomposites to increase electrical "gain" in chemical sensors," Applied Physics Letters, vol. 91, no. 20, Article ID 203111, 2007.

[48] M. du Plessis, "Nanoporous silicon explosive devices," Materials Science and Engineering B, vol. 147, no. 2-3, pp. 226-229, 2008.

[49] M. J. Sailor, in Properties of Porous Silicon, L. T. Canham, Ed., p. 364, INSPEC, London, UK, 1997.

[50] A. Halimaoui, in Properties of Porous Silicon, L. T. Canham, Ed., p. 12, INSPEC, London, UK, 1997.

[51] E. Gross, D. Kovalev, N. Künzner, et al., "Spectrally resolved electronic energy transfer from silicon nanocrystals to molecular oxygen mediated by direct electron exchange," Physical Review B, vol. 68, no. 11, Article ID 115405, 2003.

[52] U. Gösele, "Nanocrystals: shedding new light on silicon," Nature Nanotechnology, vol. 3, no. 3, pp. 134-135, 2008.

[53] G. Di Francia, V. La Ferrara, L. Lancellotti, and L. Quercia, "Porous silicon based gas sensor," Recent Research Development in Electrochemistry, vol. 3, p. 93, 2000.

[54] A. Foucaran, F. Pascal-Delannoy, A. Giani, A. Sackda, P. Combette, and A. Boyer, "Porous silicon layers used for gas sensor applications," Thin Solid Films, vol. 297, no. 1-2, pp. 317-320, 1997.

[55] A. E. Aliev, Sh. U. Yuldashev, P. K. Khabibullaev, M. H. Khan, and F. A. Khalid, "Studies on sensitivity of porous silicon surfaces to environmental gases," Journal of Materials Engineering and Performance, vol. 6, no. 2, pp. 161-164, 1997.

[56] L. A. Balagurov, B. M. Leiferov, E. A. Petrova, A. F. Orlov, and E. M. Panasenko, "Influence of water and alcohols on photoluminescence of porous silicon," Journal of Applied Physics, vol. 9, p. 7143, 1996.

[57] F. Yin, X. P. Li, Z. Z. Zhang, and X. R. Xiao, "Investigation on the surface reactivity of luminescent porous silicon," Applied Surface Science, vol. 119, no. 3-4, pp. 310-312, 1997.

[58] W. J. Jin, G. L. Shen, and R. Q. Yu, "Organic solvent induced quenching of porous silicon photoluminescence," Spectrochimica Acta Part A, vol. 54, no. 10, pp. 1407-1414, 1998. 
[59] G. Di Francia, F. De Filippo, V. La Ferrara, et al., in Proceedings of the 12th EC Solid State Trasducers, p. 544, Southampton, UK, September 1998.

[60] M. S. Salem, M. J. Sailor, K. Fukami, T. Sakka, and Y. H. Ogata, "Sensitivity of porous silicon rugate filters for chemical vapor detection," Journal of Applied Physics, vol. 103, no. 8, Article ID 083516, 2008.

[61] J. P. Clarkson, P. M. Fauchet, V. Rajalingam, and K. D. Hirschman, "Solvent detection and water monitoring with a macroporous silicon field-effect sensor," IEEE Sensors Journal, vol. 7, no. 3, pp. 329-335, 2007.

[62] V. Vrkoslav, I. Jelínek, G. Broncová, V. Král, and J. Dian, "Polypyrrole-functionalized porous silicon for gas sensing applications," Materials Science \& Engineering C, vol. 26, no. 5-7, pp. 1072-1076, 2006.

[63] I. Schechter, M. Ben-Chorin, and A. Kux, "Gas sensing properties of porous silicon," Analytical Chemistry, vol. 67, no. 20, pp. 3727-3732, 1995.

[64] G. Dolino, D. Bellet, and C. Faivre, "Adsorption strains in porous silicon," Physical Review B, vol. 54, no. 24, pp. 17919 17929, 1996.

[65] D. R. Huanca, F. J. Ramirez-Fernandez, and W. J. Salcedo, "Porous silicon optical cavity structure applied to high sensitivity organic solvent sensor," Microelectronics Journal, vol. 39, no. 3-4, pp. 499-506, 2008.

[66] M. Archer, M. Christophersen, and P. M. Fauchet, "Electrical porous silicon chemical sensor for detection of organic solvents," Sensors and Actuators B, vol. 106, pp. 347-357, 2005.

[67] T. Holec, T. Chvojka, I. Jelínek, et al., "Determination of sensoric parameters of porous silicon in sensing of organic vapors," Materials Science \& Engineering C, vol. 19, no. 1-2, pp. 251-254, 2002.

[68] J. Cerdà, A. Cirera, A. Vilà, A. Cornet, and J. R. Morante, "Deposition on micromachined silicon substrates of gas sensitive layers obtained by a wet chemical route: a $\mathrm{CO} / \mathrm{CH}_{4}$ high performance sensor," Thin Solid Films, vol. 391, no. 2, pp. 265-269, 2001.

[69] S. Jang, Y. Koh, J. Kim, and H. Sohn, "Detection of G-type nerve agent simulants based on a double reflection DBR porous silicon interferometer," Journal of the Korean Physical Society, vol. 52, no. 2, pp. 212-215, 2008.

[70] L. De Stefano, L. Moretti, I. Rendina, and L. Rotiroti, "Pesticides detection in water and humic solutions using porous silicon technology," Sensors and Actuators B, vol. 111112, pp. 522-525, 2005.

[71] R. R. Chandler-Henderson, B. Sweryda-Krawiec, and J. L. Coffer, "Steric considerations in the amine-induced quenching of luminescent porous silicon," Journal of Physical Chemistry, vol. 99, no. 21, pp. 8851-8855, 1995.

[72] E. Guillermain, V. Lysenko, R. Orobtchouk, et al., "Bragg surface wave device based on porous silicon and its application for sensing," Applied Physics Letters, vol. 90, no. 24, Article ID 241116, 2007.

[73] R. B. Bjorklund, S. Zangooie, and H. Arwin, "Planar porefilling-adsorption in porous silicon," Advanced Materials, vol. 9, no. 13, pp. 1067-1070, 1997.

[74] J. Harper and M. J. Sailor, "Photoluminescence quenching and the photochemical oxidation of porous silicon by molecular oxygen," Langmuir, vol. 13, no. 17, pp. 4652-4658, 1997.

[75] N. K. Ali, M. R. Hashim, and A. Abdul Aziz, "Effects of surface passivation in porous silicon as $\mathrm{H}_{2}$ gas sensor," SolidState Electronics, vol. 52, no. 7, pp. 1071-1074, 2008.
[76] R. Prabakaran, L. Silva, E. Fortunato, R. Martins, and I. Ferreira, "Investigation of hydrocarbon coated porous silicon using PECVD technique to detect $\mathrm{CO}_{2}$ gas," Journal of NonCrystalline Solids, vol. 354, no. 19-25, pp. 2610-2614, 2008.

[77] J. Tuura, M. Björkqvist, J. Salonen, and V.-P. Lehto, "Electrically isolated thermally carbonized porous silicon layer for humidity sensing purposes," Sensors and Actuators B, vol. 131, no. 2, pp. 627-632, 2008.

[78] S. Khoshnevis, R. S. Dariani, M. E. Azim-Araghi, Z. Bayindir, and K. Robbie, "Observation of oxygen gas effect on porous silicon-based sensors," Thin Solid Films, vol. 515, no. 4, pp. 2650-2654, 2006.

[79] P. Rivolo, P. Pirasteh, A. Chaillou, et al., "Oxidised porous silicon impregnated with Congo Red for chemical sensoring applications," Sensors and Actuators B, vol. 100, no. 1-2, pp. 99-102, 2004.

[80] L. Pancheri, C. J. Oton, Z. Gaburro, G. Soncini, and L. Pavesi, "Very sensitive porous silicon $\mathrm{NO}_{2}$ sensor," Sensors and Actuators B, vol. 89, no. 3, pp. 237-239, 2003.

[81] G. Di Francia, A. Castaldo, E. Massera, I. Nasti, L. Quercia, and I. Rea, "A very sensitive porous silicon based humidity sensor," Sensors and Actuators B, vol. 111-112, pp. 135-139, 2005.

[82] E. Massera, I. Nasti, L. Quercia, I. Rea, and G. Di Francia, "Improvement of stability and recovery time in poroussilicon-based $\mathrm{NO}_{2}$ sensor," Sensors and Actuators B, vol. 102, no. 2, pp. 195-197, 2004.

[83] N. K. Ali, M. R. Hashim, and A. Abdul Aziz, "Effects of surface passivation in porous silicon as $\mathrm{H}_{2}$ gas sensor," SolidState Electronics, vol. 52, no. 7, pp. 1071-1074, 2008.

[84] S. E. Lewis, J. R. Deboer, J. L. Gole, and P. J. Hesketh, "Sensitive, selective, and analytical improvements to a porous silicon gas sensor," Sensors and Actuators B, vol. 110, no. 1, pp. 54-65, 2005.

[85] F. Rahimi and A. Iraji zad, "Characterization of Pd nanoparticle dispersed over porous silicon as a hydrogen sensor," Journal of Physics D, vol. 40, no. 23, pp. 7201-7209, 2007.

[86] Be. Mahmoudi, N. Gabouze, L. Guerbous, M. Haddadi, H. Cheraga, and K. Beldjilali, "Photoluminescence response of gas sensor based on $\mathrm{CHx}$ /porous silicon-effect of annealing treatment," Materials Science and Engineering B, vol. 138, no. 3, pp. 293-297, 2007.

[87] D. R. Huanca, F. J. Ramirez-Fernandez, and W. J. Salcedo, "Porous silicon optical cavity structure applied to high sensitivity organic solvent sensor," Microelectronics Journal, vol. 39, no. 3-4, pp. 499-506, 2008.

[88] J.-I. Hahm and C. M. Lieber, "Direct ultrasensitive electrical detection of DNA and DNA sequence variations using nanowire nanosensors," Nano Letters, vol. 4, no. 1, pp. 51-54, 2004.

[89] G. Di Francia, V. La Ferrara, S. Manzo, and S. Chiavarini, "Towards a label-free optical porous silicon DNA sensor," Biosensors and Bioelectronics, vol. 21, no. 4, pp. 661-665, 2005.

[90] X. T. Zhou, J. Q. Hu, C. P. Li, D. D. D. Ma, C. S. Lee, and S. T. Lee, "Silicon nanowires as chemical sensors," Chemical Physics Letters, vol. 369, no. 1-2, pp. 220-224, 2003.

[91] J. Jie, W. Zhang, K. Peng, G. Yuan, C. S. Lee, and S.T. Lee, "Surface-dominated transport properties of silicon nanowires," Advanced Functional Materials, vol. 18, no. 20, pp. 3251-3257, 2008.

[92] F. Patolsky and C. M. Lieber, "Nanowire nanosensors," Materials Today, vol. 8, no. 4, pp. 20-28, 2005. 
[93] R. Sze, Semiconductor Sensor, John Wiley \& Sons, New York, NY, USA, 1994.

[94] M. Law, H. Kind, B. Messer, F. Kim, and P. Yang, "Photochemical sensing of $\mathrm{NO}_{2}$ with $\mathrm{SnO}_{2}$ nanoribbon nanosensors at room temperature," Angewandte Chemie International Edition, vol. 41, no. 13, pp. 2405-2408, 2002.

[95] E. Comini, G. Faglia, G. Sberveglieri, Z. Pan, and Z. L. Wang, "Stable and highly sensitive gas sensors based on semiconducting oxide nanobelts," Applied Physics Letters, vol. 81, no. 10, p. 1869, 2002.

[96] A. Kolmakov, Y. Zhang, G. Cheng, and M. Moskovits, "Detection of $\mathrm{CO}$ and $\mathrm{O}_{2}$ using tin oxide nanowire sensors," Advanced Materials, vol. 15, no. 12, pp. 997-1000, 2003.

[97] G. Neri, A. Bonavita, G. Micali, et al., "Ethanol sensors based on Pt-doped tin oxide nanopowders synthesised by gel-combustion," Sensors and Actuators B, vol. 117, no. 1, pp. 196-204, 2006.

[98] L. L. Fields, J. P. Zheng, Y. Cheng, and P. Xiong, "Roomtemperature low-power hydrogen sensor based on a single tin dioxide nanobelt," Applied Physics Letters, vol. 88, no. 26, Article ID 263102, 2006.

[99] A. Chen, X. Huang, Z. Tong, S. Bai, R. Luo, and C. C. Liu, "Preparation, characterization and gas-sensing properties of $\mathrm{SnO}_{2}-\mathrm{In}_{2} \mathrm{O}_{3}$ nanocomposite oxides," Sensors and Actuators $B$, vol. 115, no. 1, pp. 316-321, 2006.

[100] M. Rumyantseva, V. Kovalenko, A. Gaskov, et al., "Nanocomposites $\mathrm{SnO}_{2} / \mathrm{Fe}_{2} \mathrm{O}_{3}$ : sensor and catalytic properties," Sensors and Actuators B, vol. 118, no. 1-2, pp. 208-214, 2006.

[101] J. Arbiol, J. R. Morante, P. Bouvier, et al., " $\mathrm{SnO}_{2} / \mathrm{MoO}_{3}$ nanostructure and alcohol detection," Sensors and Actuators $B$, vol. 118, no. 1-2, pp. 156-162, 2006.

[102] Q. Kuang, C. Lao, Z. L. Wang, Z. Xie, and L. Zheng, "High-sensitivity humidity sensor based on a single $\mathrm{SnO}_{2}$ nanowire," Journal of the American Chemical Society, vol. 129, no. 19, pp. 6070-6071, 2007.

[103] N. Mangkorntong and M. Thepnurat, "A single $\mathrm{SnO}_{2}$, nanowire gas sensor," Chiang Mai University Journal of Natural Sciences, vol. 7, pp. 165-170, 2008.

[104] Y. Shen, T. Yamazaki, Z. Liu, et al., "Microstructure and $\mathrm{H}_{2}$ gas sensing properties of undoped and Pd-doped $\mathrm{SnO}_{2}$ nanowires," Sensors and Actuators B, vol. 135, no. 2, pp. 524$529,2009$.

[105] A. Kolmakov, X. Chen, and M. Moskovits, "Functionalizing nanowires with catalytic nanoparticles for gas sensing application," Journal of Nanoscience and Nanotechnology, vol. 8, no. 1, pp. 111-121, 2008.

[106] Q. Wan, J. Huang, Z. Xie, T. Wang, E. N. Dattoli, and W. Lu, "Branched $\mathrm{SnO}_{2}$ nanowires on metallic nanowire backbones for ethanol sensors application," Applied Physics Letters, vol. 92, no. 10, Article ID 102101, 2008.

[107] Q. H. Li, Y. X. Liang, Q. Wan, and T. H. Wang, "Oxygen sensing characteristics of individual $\mathrm{ZnO}$ nanowire transistors," Applied Physics Letters, vol. 85, no. 26, pp. 6389-6391, 2004.

[108] T. Gao and T. H. Wang, "Synthesis and properties of multipod-shaped $\mathrm{ZnO}$ nanorods for gas-sensor applications," Applied Physics A, vol. 80, no. 7, pp. 1451-1454, 2005.

[109] H. T. Wang, B. S. Kang, F. Ren, et al., "Hydrogen-selective sensing at room temperature with $\mathrm{ZnO}$ nanorods," Applied Physics Letters, vol. 86, no. 24, Article ID 243503, 3 pages, 2005.

[110] H. Cheng, L. Qin, and Q.-M. Wang, "P1D-2 high temperature langasite $\mathrm{BAW}$ gas sensor based on $\mathrm{ZnO}$ nano wire arrays," in Proceedings of IEEE Ultrasonics Symposium (IUS '07), pp. 1361-1364, New York, NY, USA, October 2007.
[111] H. Tang, M. Yan, H. Zhang, et al., "A selective $\mathrm{NH}_{3}$ gas sensor based on $\mathrm{Fe}_{2} \mathrm{O}_{3}-\mathrm{ZnO}$ nanocomposites at room temperature," Sensors and Actuators B, vol. 114, no. 2, pp. 910-915, 2006.

[112] W. Wongka, S. Yata, A. Gardchareon, P. Mangkorntong, N. Mangkorntong, and S. Choopun, "Zinc oxide nanowires impregnated with platinum and gold nanoparticle for ethanol sensor," Chiang Mai University Journal of Natural Sciences, vol. 7, no. 1, pp. 185-190, 2008.

[113] E. Comini, M. Ferroni, N. Poli, et al., "Doped $\mathrm{ZnO}$ nanowires: towards homojuctions," in Proceedings of IEEE Sensors Conference, pp. 835-838, Lecce, Italy, October 2008.

[114] D. Zhang, Z. Liu, C. Li, et al., "Detection of $\mathrm{NO}_{2}$ down to ppb levels using individual and multiple $\mathrm{In}_{2} \mathrm{O}_{3}$ nanowire devices," Nano Letters, vol. 4, no. 10, pp. 1919-1924, 2004.

[115] E. C. Walter, K. Ng, M. P. Zach, R. M. Penner, and F. Favier, "Electronic devices from electrodeposited metal nanowires," Microelectronic Engineering, vol. 61-62, pp. 555-561, 2002.

[116] F. Favier, E. C. Walter, M. P. Zach, T. Benter, and R. M. Penner, "Hydrogen sensors and switches from electrodeposited palladium mesowire arrays," Science, vol. 293, no. 5538, pp. 2227-2231, 2001.

[117] E. C. Walter, F. Favier, and R. M. Penner, "Palladium mesowire arrays for fast hydrogen sensors and hydrogenactuated switches," Analytical Chemistry, vol. 74, no. 7, pp. 1546-1553, 2002.

[118] B. J. Murray, E. C. Walter, and R. M. Penner, "Amine vapor sensing with silver mesowires," Nano Letters, vol. 4, no. 4, pp. 665-670, 2004.

[119] C. Cheng, R. K. Gonela, Q. Gu, and D. T. Haynie, "Selfassembly of metallic nanowires from aqueous solution," Nano Letters, vol. 5, no. 1, pp. 175-178, 2005.

[120] V. La Ferrara, B. Alfano, E. Massera, and G. Di Francia, "Palladium nanowires assembly by dielectrophoresis investigated as hydrogen sensors," IEEE Transactions on Nanotechnology, vol. 7, no. 6, pp. 776-781, 2008.

[121] M. Penza, G. Cassano, P. Aversa, et al., "Alcohol detection using carbon nanotubes acoustic and optical sensors," Applied Physics Letters, vol. 85, no. 12, pp. 2379-2381, 2004.

[122] H.-K. Liao, E.-S. Yang, J.-C. Chou, W.-Y. Chung, T.-P. Sun, and S.-K. Hsiung, "Temperature and optical characteristics of tin oxide membrane gate ISFET," IEEE Transactions on Electron Devices, vol. 46, no. 12, pp. 2278-2281, 1999.

[123] H.-W. Chen, R.-J. Wu, K.-H. Chan, Y.-L. Sun, and P.-G. Su, "The application of CNT/Nafion composite material to low humidity sensing measurement," Sensors and Actuators B, vol. 104, no. 1, pp. 80-84, 2005.

[124] A. Jungen, C. Meder, M. Tonteling, C. Stampfer, R. Linderman, and C. Hierold, "A MEMS actuator for integrated carbon nanotube strain sensing," in Proceedings of IEEE Sensors Conference, pp. 1-4, Irvine, Calif, USA, OctoberNovember 2005.

[125] S. Deshpande, A. Karakoti, G. Londe, H. J. Cho, and S. Seal, "Room temperature hydrogen detection using 1-D nanostructured tin oxide sensor," Journal of Nanoscience and Nanotechnology, vol. 7, no. 9, pp. 3354-3357, 2007.

[126] P. Bhattacharyya, P. K. Basu, B. Mondal, and H. Saha, "A low power MEMS gas sensor based on nanocrystalline $\mathrm{ZnO}$ thin films for sensing methane," Microelectronics Reliability, vol. 48, no. 11-12, pp. 1772-1779, 2008.

[127] M. Penza, M. A. Tagliente, P. Aversa, M. Re, and G. Cassano, "The effect of purification of single-walled carbon nanotube bundles on the alcohol sensitivity of nanocomposite Langmuir-Blodgett films for SAW sensing applications," Nanotechnology, vol. 18, no. 18, Article ID 185502, 2007. 
[128] S. Sivaramakrishnan, R. Rajamani, C. S. Smith, K. A. McGee, K. R. Mann, and N. Yamashita, "Carbon nanotube-coated surface acoustic wave sensor for carbon dioxide sensing," Sensors and Actuators B, vol. 132, no. 1, pp. 296-304, 2008.

[129] A. A. Pesetski, J. E. Baumgardner, E. Folk, J. X. Przybysz, J. D. Adam, and H. Zhang, "Carbon nanotube field-effect transistor operation at microwave frequencies," Applied Physics Letters, vol. 88, no. 11, Article ID 113103, 2006.

[130] M. S. Arnold, P. Avouris, Z. W. Pan, and Z. L. Wang, "Fieldeffect transistors based on single semiconducting oxide nanobelts," Journal of Physical Chemistry B, vol. 107, no. 3, pp. 659-663, 2003.

[131] S. Dasgupta, S. Gottschalk, R. Kruk, and H. Hahn, "A nanoparticulate indium tin oxide field-effect transistor with solid electrolyte gating," Nanotechnology, vol. 19, no. 43, Article ID 435203, 2008.

[132] C. S. Lao, Q. Kuang, Z. L. Wang, M.-C. Park, and Y. Deng, "Polymer functionalized piezoelectric-FET as humidity/chemical nanosensors," Applied Physics Letters, vol. 90, no. 26, Article ID 262107, 2007.

[133] G. Barillaro, A. Diligenti, L. M. Strambini, E. Comini, and G. Faglia, "FET-like silicon sensor with a porous layer for $\mathrm{NO}_{2}$ detection," in Proceedings of IEEE Sensors Conference, pp. 121-124, Irvine, Calif, USA, October-November 2005.

[134] H. C. Wang, Y. Li, and M. J. Yang, "Fast response thin film $\mathrm{SnO}_{2}$ gas sensors operating at room temperature," Sensors and Actuators B, vol. 119, no. 2, pp. 380-383, 2006.

[135] M. Kroneld, S. Novikov, S. Saukko, P. Kuivalainen, P. Kostamo, and V. Lantto, "Gas sensing properties of $\mathrm{SnO}_{2}$ thin films grown by MBE," Sensors and Actuators B, vol. 118, no. 1-2, pp. 110-114, 2006.

[136] L. Rotkina, J.-F. Lin, and J. P. Bird, "Nonlinear currentvoltage characteristics of $\mathrm{Pt}$ nanowires and nanowire transistors fabricated by electron-beam deposition," Applied Physics Letters, vol. 83, no. 21, pp. 4426-4428, 2003.

[137] T.-Y. Choi, B. Kang, and D. Poulikakos, "Focused ion beam in thermal science and engineering," Microscopy and Microanalysis, vol. 13, supplement 2, pp. 1498-1499, 2007. 

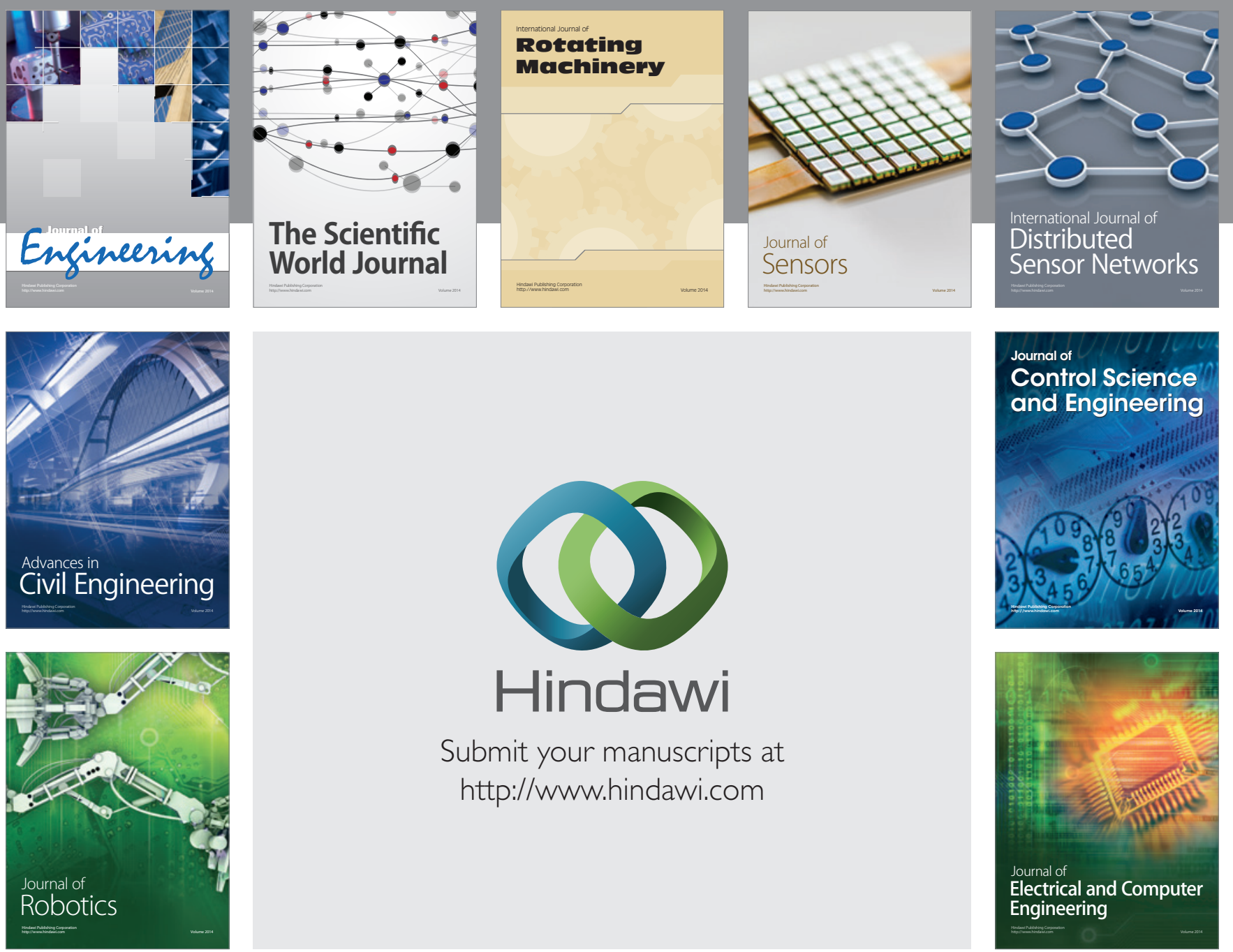

Submit your manuscripts at

http://www.hindawi.com
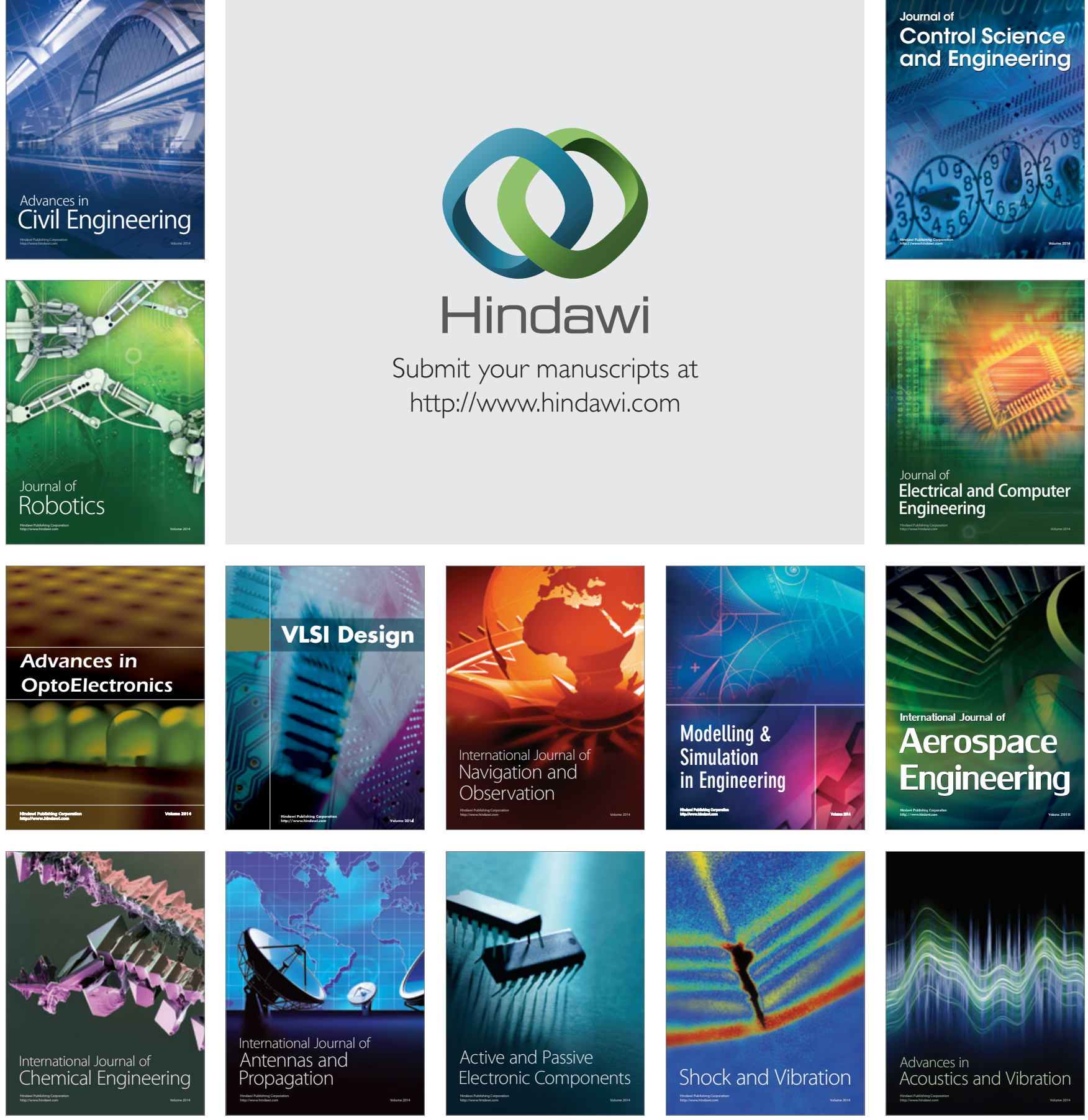